\title{
Diversité fonctionnelle et spatiale des campements paléolithiques et mésolithiques dans la Polésie de Lublin (Pologne)
}

Spatial and functional Diversity of Palaeolithic and Mesolithic camps in Polesie, Lublin (Poland)

Tomasz Boron

\section{OpenEdition}

Journals

Édition électronique

URL : http://journals.openedition.org/paleo/2535

DOI : $10.4000 /$ paleo.2535

ISSN : 2101-0420

Éditeur

SAMRA

Édition imprimée

Date de publication : 15 décembre 2013

Pagination : 47-78

ISSN : 1145-3370

Référence électronique

Tomasz Boron, « Diversité fonctionnelle et spatiale des campements paléolithiques et mésolithiques dans la Polésie de Lublin (Pologne) », PALEO [En ligne], 24 | 2013, mis en ligne le 17 avril 2014, consulté le 07 juillet 2020. URL : http://journals.openedition.org/paleo/2535; DOI : https://doi.org/10.4000/ paleo.2535

Ce document a été généré automatiquement le 7 juillet 2020

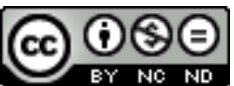

PALEO est mis à disposition selon les termes de la licence Creative Commons Attribution - Pas d'Utilisation Commerciale - Pas de Modification 4.0 International. 


\section{Diversité fonctionnelle et spatiale des campements paléolithiques et mésolithiques dans la Polésie de Lublin (Pologne)}

Spatial and functional Diversity of Palaeolithic and Mesolithic camps in Polesie, Lublin (Poland)

Tomasz Boron

\section{Introduction}

1 L'analyse fonctionnelle et spatiale qui fait l'objet du présent article est basée sur l'étude du matériel archéologique mis au jour au cours de travaux sur le site de Nieborowa dans le sud-est de la Pologne (fig. 1-1). L'ensemble des sites de Nieborowa (I, II, III) se trouve à la limite de trois régions bien distinctes tant sur le plan géographique qu'environnemental et paysager: Pagóry Chełmskie (collines de Chełm), Pojezierze ŁĘczyńsko-Włodawskie (lacs de ŁĘczna et Włodawa) et Obniżenie Dubienki (bas-fond de Dubienka) (fig. 1-2).

2 Le bassin de la Vistule, dans ses zones sud et centre, représente la zone d'occupation la plus dense de de la culture de Janislawice (Kozłowski 2007- p. 111) (fig.1-1).

Le site archéologique de Nieborowa a été découvert dans les années 1962-1963 lors de travaux de surface organisés par l'Institut d'histoire de la culture matérielle (actuellement IEA PAN : l'Institut d'Archéologie et d'Ethnologie de l'Académie polonaise des sciences) sous la direction de Monsieur le Professeur docteur d'État, Waldemar Chmielewski.

4 Les fouilles archéologiques y ont été menées entre 1964 et 1977 par Halina Mackiewicz d'IAE PAN. Elles ont livré un riche matériel en silex et en céramique, fortement 
diversifié et appartenant à différentes cultures, du Paléolithique final au premier Âge du fer inclus.

5 Le site de Nieborowa I est situé sur un versant sablonneux et une telle configuration spatiale ne laisse subsister que de menus ossements d'animaux brûlés et des charbons de bois, sans autres vestiges en matières organiques. Le matériel archéologique a été identifié jusqu'à $120 \mathrm{~cm}$ sous la surface.

6 Compte tenu de la qualité des recherches effectuées, le matériel lithique mis au jour sur le site est une source précieuse et fiable pour l'étude de l'aménagement de l'espace dans les campements des Âges de pierre et des métaux.

7 Un des critères essentiels dans la reconstitution et l'interprétation des structures d'habitat est l'homogénéité des objets mobiliers qui, lorsqu'ils apparaissent sous forme de petites concentrations compactes de silex, constituent un argument de poids attestant de l'uniformité culturelle de celles-ci (Schild, Marczak, Królik 1975 - p. 37 ; Grön 1987- p.65). Résistant mieux à la dégradation que les objets en matières organiques (Andrefsky Jr. 2009 - p. 65), les objets lithiques représentent généralement la majorité des artefacts dégagés sur des sites archéologiques et restent, de loin, les vestiges matériels les plus aptes à fournir des données pour l'analyse spatiale des campements.

Partant de l'étude de ces vestiges lithiques, notre analyse spatiale s'appuie sur leur distribution horizontale (Schild 1980 - p. 79-80), et en particulier celle des déchets de fabrication d'outils (burins, microburins). Il est communément admis que ceux-ci indiquent les lieux de fabrication d'outils (Olive 1997 - p. 91-92 ; Fiedorczuk 2006 - p. 30) car, en règle générale, on les retrouve en dépôt primaire - primary refuse (Schiffer 1976 p. 30). Vu leurs petites dimensions, ils sont moins sensibles aux facteurs extérieurs pouvant par exemple causer des dislocations horizontales (Olausson 1986 - p. 21).

9 Le rapport entre le dépôt d'objets en silex et leur lieu d'utilisation est beaucoup plus complexe, comme en témoigne la distribution spatiale des vestiges observée au niveau 4, tranchée 9, à Całowanie où, une fois le travail fini, les outils ont été rejetés (Schild 1984 - p. 230, fig. 4-2,3).

10 La méthode permettant de reconnaître les différentes aires d'activités, puis de les enregistrer et de définir leurs relations spatio-temporelles est celle des remontages de vestiges lithiques (Tomaszewski 1986 - p. 257-273), comme en témoigne par exemple celle faite sur le site de Meer II (Cahen, Keeley, Van Noten 1979 - fig. 8,9) ; Cahen 1984 p. 247). Dans notre étude, conformément à la proposition de E. Cziesla (1990 - p. 9-10), les liaisons entre artefacts remontés sont indiquées par trois traits différents.

11 Les objets mobiliers pris en compte ici représentent différentes phases d'occupation de la microrégion de Nieborowa. Les plus anciens appartiennent aux ensembles mazoviens (culture swiderienne) et sont datés d'environ 10800 à 9700 BP (Schild 1996 - p. 135). Notre choix s'est porté sur deux d'entre eux, découverts dans les tranchées 4 et $9 \mathrm{du}$ site de Nieborowa I (fig 1-3). L'analyse a également intégré des mobiliers mésolithiques de la culture de Janislavice entre 7300 BP (Szymczak 2003 - p. 13-14) et environ 5600 $5500 \mathrm{BP}$.

12 Selon la périodisation de la culture janislavicienne (Galiński 1997 - p. 204-211, 2002 p. 280-289), l'horizon le plus ancien présente des assemblages sans trapèzes qui pourraient être datés au début de l'Atlantique (7500 BP - 7000 BP) (Galiński 2002 p. 285 ; Kozłowski 1972 - p. 159, 1989 - p. 156). Ce type d'assemblage, outre Nieborowa, 
se retrouve sur deux autres sites : la tombe de Janisławice (Chmielewska 1954 - p. 23-48) et de Wistka Szlachecka II/1960 (Schild, Marczak, Królik 1975 - p. 127-129).

13 L'étape suivante de l'épanouissement de la culture janislavicienne est marquée par la présence d'industries classiques à trapèzes attestées ici par le matériel provenant de la tranchée 8.

14 Les vestiges issus des tranchées 1 et 2 (site de Nieborowa III) ont été classés parmi les matériels lithiques janislawiciens chronologiquement les plus récents (dits parfois assemblages de type Baraki Stare) et qui se caractérisent par la présence de triangles petits et étroits (Galiński 2002 - p. 287).

15 La dernière étape de l'occupation mésolithique à Nieborowa est représentée par les assemblages datant de la période atlantique finale. Leur trait commun est une dominante très nette des trapèzes et des outils éclats (racloirs, éclats retouchés, grattoirs).

16 Les dates obtenues sur des charbons de bois $(7250 \pm 50 \mathrm{BP}\{\mathrm{Poz}-18718\}$ - tranchée 2; $7120 \pm 70 \mathrm{BP}\{\mathrm{Gd}$ II61 $\}$ - tranchée $6 ; 7010 \pm 40 \mathrm{BP}\{\mathrm{Poz}-18719\}$ - tranchée 9) montrent que les débuts de l'occupation janislanicienne à Nieborowa sont contemporains de la fin de la phase ancienne de l'Atlantique. L'âge des industries à trapèzes (industries postjanislaviciennes) de la tranchée 2 du site Nieborowa I est à situer au milieu de la phase finale de cette période $5730 \pm 130 \mathrm{BP}\{\mathrm{Gd} 144\}$.

17 Les analyses spatiale et fonctionnelle des occupations de la culture janislawicienne à Nieborowa ont été faites sur la base du matériel en silex provenant des tranchées 4 et 7 (assemblages classiques, non trapèzes) ainsi que des tranchées 2 et 3 (industries postjanislaviciennes) (fig. 1-3). 
Figure 1

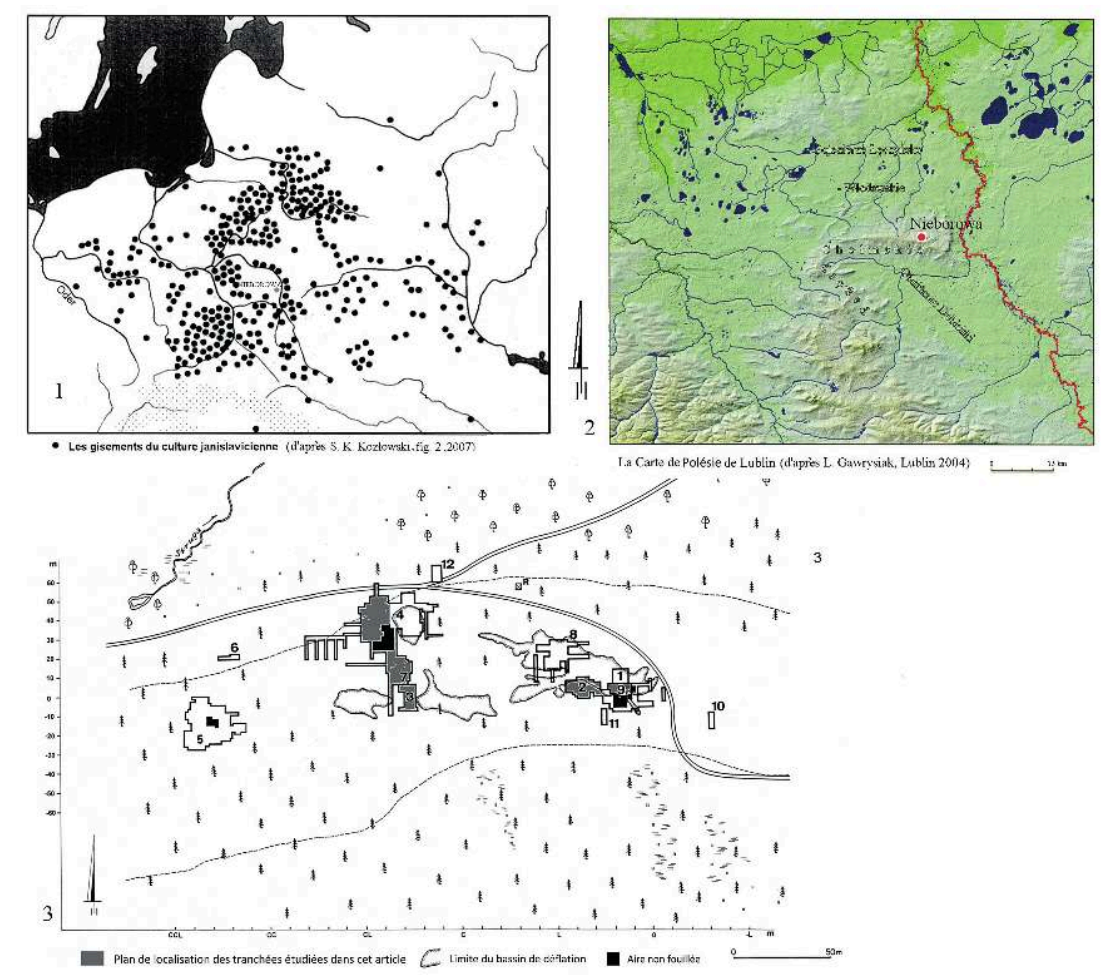

1 - Localisation géographique du gisement de Nieborowa ; 2 - Localisation du gisement de Nieborowa dans la Polésie de Lublin ; 3 - Nieborowa I. Plan général des fouilles.

\section{1 - Analyse spatiale et fonctionnelle}

Pour plus de clarté, l'analyse spatiale et fonctionnelle des occupations sera présentée dans l'ordre chronologique.

\section{1 - Occupation mazovienne}

19 La tranchée 4 de $757 \mathrm{~m} 2$ a été explorée pendant les campagnes 1965-1967. Elle a été divisée en trois zones : les secteurs I, II et de déflation.

Le secteur I comporte deux concentrations de silex A et C. Le secteur II une seule concentration, B. L'analyse spatiale portera sur les secteurs I, Mésolithique seul (culture janislavicienne) et II, Paléolithique (occupation mazovienne) et Mésolithique (culture janislavicienne) (fig. 2-1). 
Figure 2 - Nieborowa I.

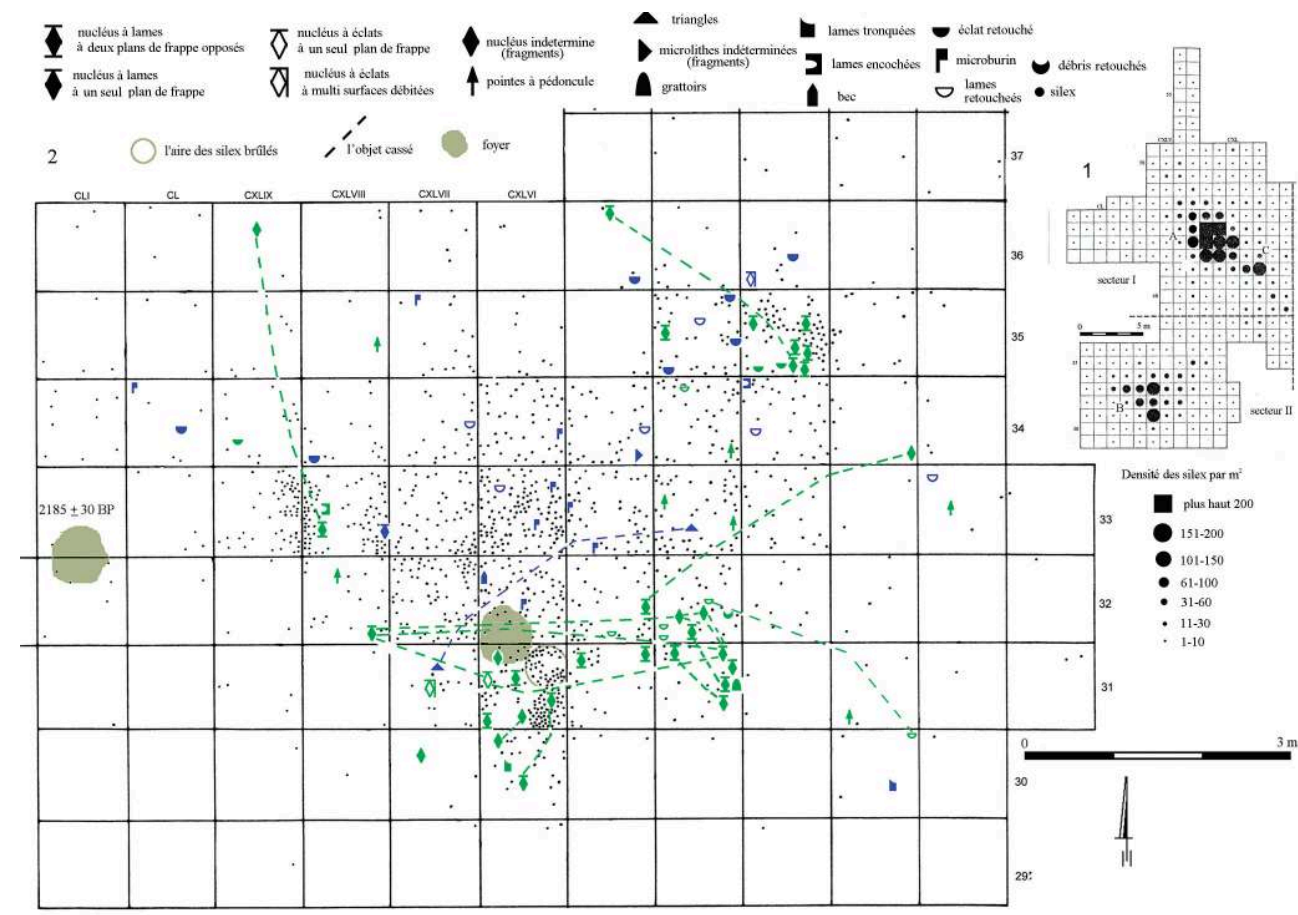

1 - plan de la tranchée $4 ; 2$ - tranchée 4, secteur II. Répartition des objets (les objets du Paléolithique sont en vert, ceux du Mésolithique, en bleu).

\subsection{1 - Tranchée 4 Secteur II}

Le secteur II se trouve dans la partie sud de la tranchée. Le matériel lithique formait à cet endroit une assez grande concentration $(30 \mathrm{~m} 2)$, désignée par la lettre $B$, et caractérisée par une distribution assez régulière d'artefacts (fig. 2-2). Le matériel archéologique a permis de conclure à la présence de traces d'occupations mazovienne et janislawicienne. L'inventaire mazovien compte onze pointes à pédoncule (fig. 5-3,8), un grattoir (fig. 5-9), une lame à encoche (fig. 5-10), des éclats et lames retouchées, des nucléus et des supports (éclats et lames) (tabl. 1). 
Tableau 1 - Produits en silex mazovien.

\begin{tabular}{|c|c|c|}
\hline & $\begin{array}{l}\text { Tranchée } 4 \\
\text { (secteur II) }\end{array}$ & Tranchée 9 \\
\hline & \multicolumn{2}{|c|}{ Nucléus } \\
\hline $\begin{array}{l}\text { Nucléus à lames à deux plans de frappe } \\
\text { opposés }\end{array}$ & 14 & 9 \\
\hline Nucléus à lames à un seul plan de frappe & 14 & \\
\hline Nucléus à éclats à un seul plan de frappe & 2 & \\
\hline Nucléus indéterminé (fragments) & 1 & \\
\hline \multicolumn{3}{|l|}{ Supports éclats } \\
\hline Ėclats & 203 & 154 \\
\hline $\begin{array}{l}\text { Ravivages de plan de frappe } \\
\text { Éclat à crête }\end{array}$ & 14 & $\begin{array}{c}28 \\
1\end{array}$ \\
\hline \multicolumn{3}{|c|}{ Supports laminaires } \\
\hline Lames & 123 & 89 \\
\hline Lames à crête & 36 & 12 \\
\hline Chasse-lame & 5 & 1 \\
\hline Ravivages de plan de frappe & 1 & \\
\hline $\begin{array}{l}\text { Lames sur nucléus à deux plans } \\
\text { de frappe opposés }\end{array}$ & 2 & 2 \\
\hline \multicolumn{3}{|c|}{ Fragments de lames } \\
\hline proximales & 85 & 65 \\
\hline centrales & 78 & 44 \\
\hline distales & 58 & 45 \\
\hline \multicolumn{3}{|l|}{ Outils } \\
\hline Pointes à pédoncules & 11 & 2 \\
\hline Grattoirs & 1 & 1 \\
\hline Lames tronquées & 1 & \\
\hline Lames encochées & 1 & \\
\hline Lames retouchées & 5 & 5 \\
\hline Ėclats retouchés & 3 & \\
\hline Débris retouchés & 1 & \\
\hline
\end{tabular}

22 Quatre postes de débitage (fig. 3 - 1 à 4) appartiennent à cette occupation. Ils contiennent des déchets de mise en forme et de débitage de nucléus. Deux autres postes (A, B ; fig. 2-1) se signalent par des produits qui ont été transférés à un endroit éloigné d'environ $10 \mathrm{~m}$, situé dans le secteur I (Boroń 2006 - p. 20-21). Douze blocs ont pu être remontés dont cinq permettant de localiser les postes de débitage (les silex tirés de nucléus débités avaient été laissés sur place) et sept illustrant les relations spatiales entre le lieu de débitage dans la concentration $B$ et le dépôt secondaire, le déblai éloigné est situé dans le secteur I (fig. 3-1,2,3,4). 
Figure 3 - Nieborowa I, tranchée 4, secteur II. Mazovien. Plan de localisation des remontages lithiques.

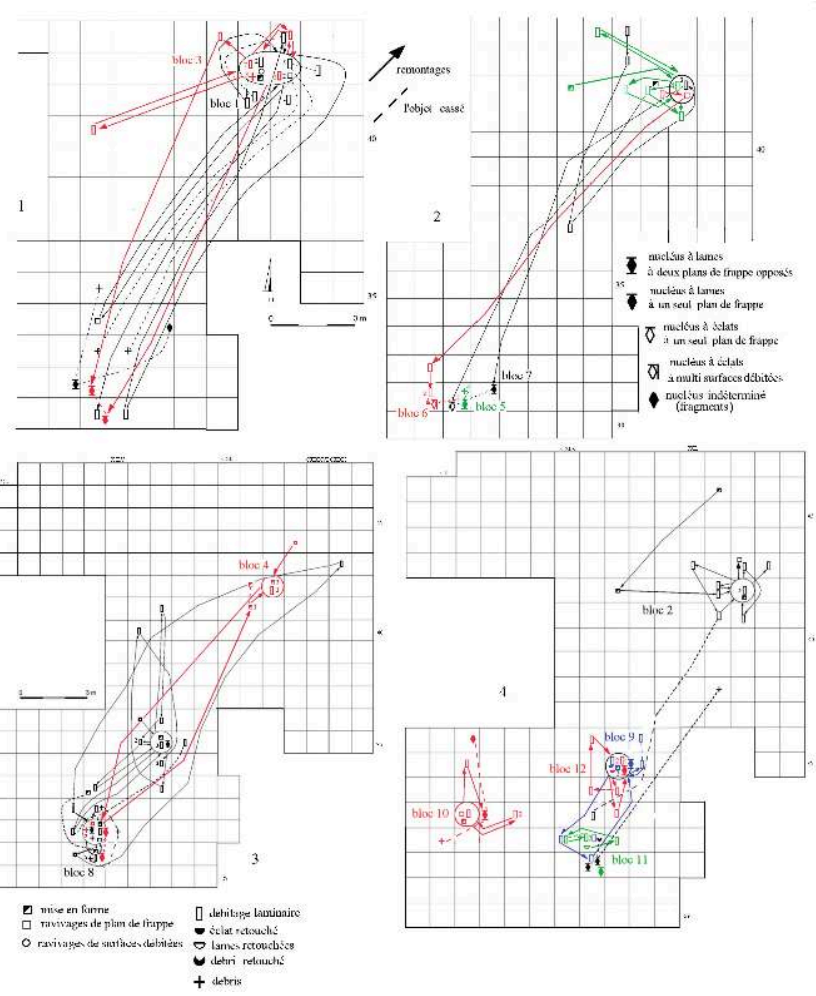

Le matériel lithique permet de conclure à l'existence d'un cycle complet de débitage, du dégrossissage et la mise en forme jusqu'à l'étape finale d'exploitation (fig. 4-1,2,3). Les nucléus sont restés sur place, à l'endroit où ils avaient été débités, ce qui est aussi le cas des blocs 1, 2, 3, 4, 5, 6 et 7 dont les supports ont été rejetés. 
Figure 4 - Nieborowa I, tranchée 4, secteur II. Mazovien.

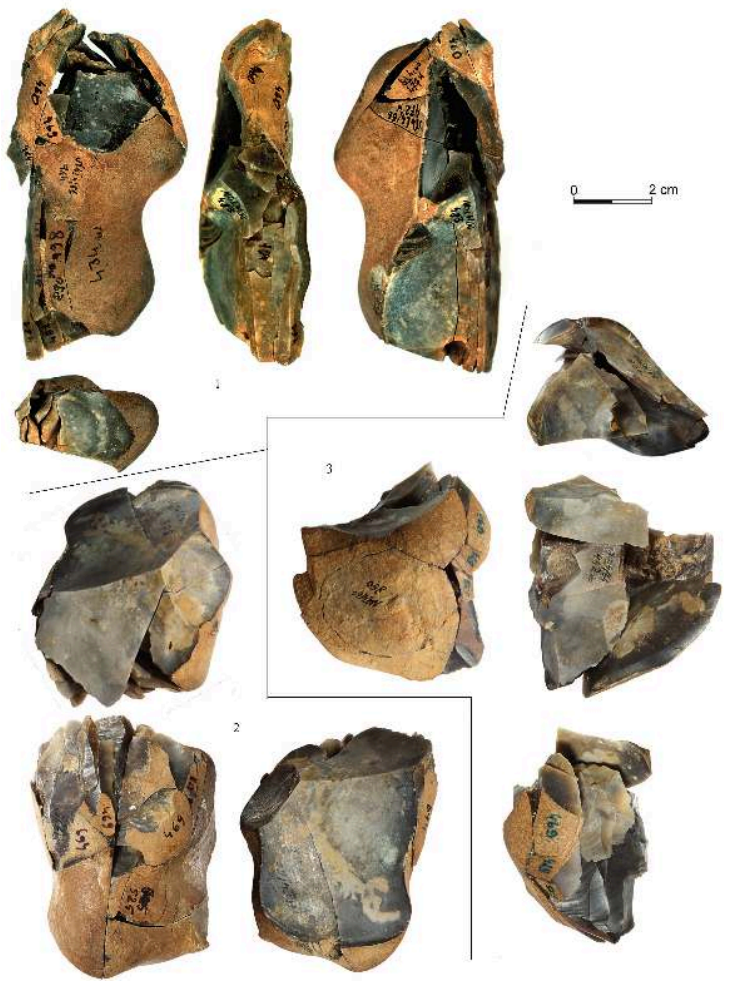

1 - bloc en silex $n^{0} 1 ; 2$ - bloc en silex $n^{0} 3 ; 3$ - bloc en silex $n^{0} 5$

Diversité fonctionnelle et spatiale des campements paléolithiques et mésolithiques dans la Polésie de Lublin (Pologne)

L'évacuation du matériel lithique est connue sur de nombreux sites paléolithiques. Elle peut être liée au nettoyage de surface, par exemple autour du foyer, comme c'est le cas du site d'Étiolles (Taborin 1994 - p. 136-137) ou au déblaiement des restes de postes de débitage (Bodu, Karlin, Ploux 1990 - p. 144-146) (fig. 5-1). 
Figure 5 - Nieborowa I, tranchée 4, secteur II.
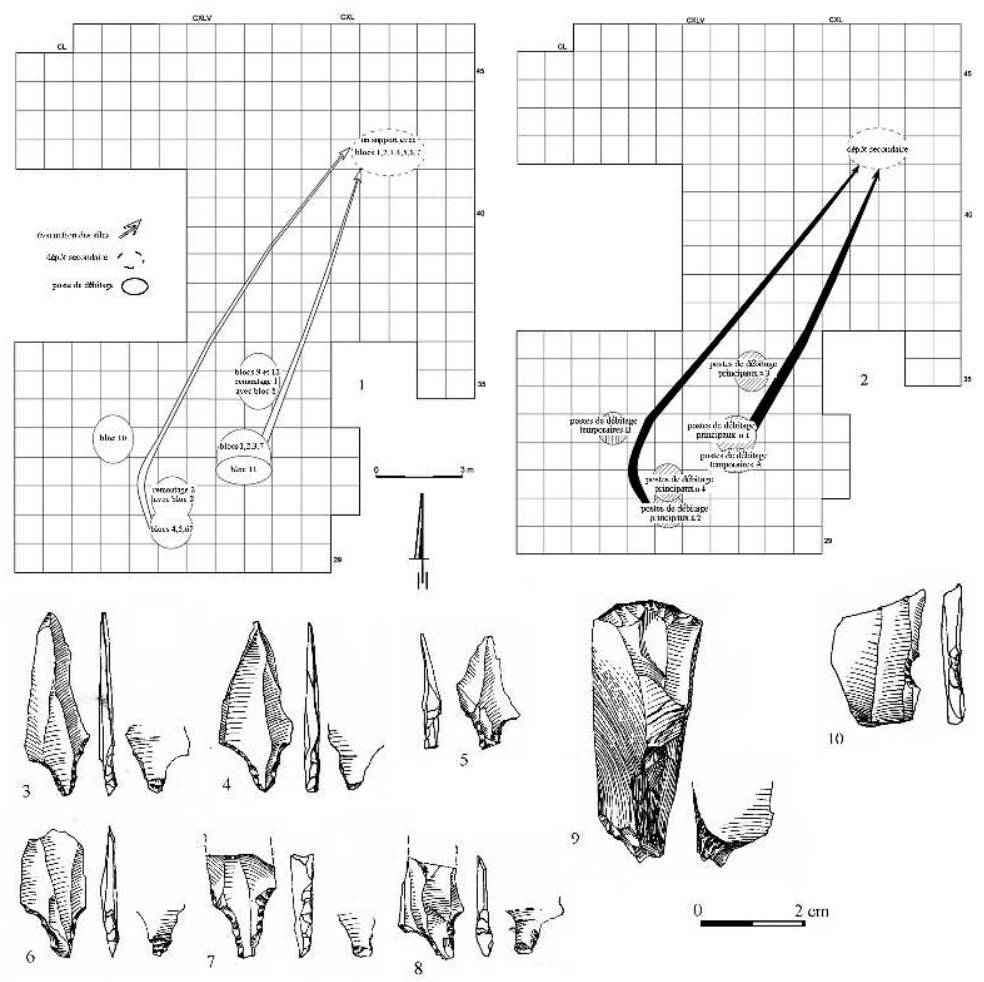

1 - poste de débitage (blocs $\left.n^{\circ} 1-12\right) ; 2$ - plan de synthèse de l'organisation spatiale ; 3-8 - pointes à pédoncule ; 9 - grattoir ; 10 - lame encochée.

Plusieurs arguments viennent à l'appui de l'hypothèse selon laquelle la concentration C est un dépôt secondaire, notamment l'absence de nucléus (fig. 2). Parmi les blocs remontés, on observe la prédominance de produits provenant de la concentration $\mathrm{C}$ (tabl. 2). Les produits venant des séquences de mise en forme et d'exploitation sont le plus souvent séparés par un objet originaire de la concentration B. Argument majeur, des remontages ont pu être réalisés avec de menus débris $(2-3 \mathrm{~mm})$ provenant de la concentration B et des supports (lames et éclats) du dépôt secondaire. 
Tableau 2 - Nieborowa I, tranchée 4, secteur II. Mazovienne. Liste des produits de blocs complexes.

\begin{tabular}{|c|c|c|}
\hline & $\begin{array}{l}\text { Tranchée 4, secteur I } \\
\text { dépôt secondaire }\end{array}$ & $\begin{array}{l}\text { Tranchée 4, secteur II } \\
\text { postes de débitage }\end{array}$ \\
\hline Bloc $n^{\circ} 1$ & $\begin{array}{l}\text { - mise en forme }-1 \text { pièce } \\
\text { - débitage de lames - } 9 \text { pièces } \\
\text { - ravivages de plan de frappe et } \\
\text { surface débitée }-3 \text { pièces }\end{array}$ & $\begin{array}{l}\text { - nucléus - } 1 \text { pièce } \\
\text { - fragment de nucléus }-1 \text { pièce } \\
\text { - débitage de lames }-2 \text { pièces } \\
\text { - ravivage de plan de frappe - } 1 \\
\text { pièce } \\
\text { - débris - } 3 \text { pièces }\end{array}$ \\
\hline Bloc $n^{\circ} 2$ & $\begin{array}{l}\text { - mise en forme - } 3 \text { pièces } \\
\text { - débitage de lames - } 12 \text { pièces } \\
\text { - ravivage de plan de frappe - } \\
1 \text { pièce. }\end{array}$ & $\begin{array}{l}\text { - nucléus - } 2 \text { pièces } \\
\text { - débitage de lames - } 1 \text { pièce } \\
\text { - débris retouché }-1 \text { pièce }\end{array}$ \\
\hline Bloc $n^{\circ} 3$ & $\begin{array}{l}\text { - débitage de lames - } 14 \text { pièces } \\
\text { - débris - } 3 \text { pièces }\end{array}$ & $\begin{array}{l}\text { - nucléus }-2 \text { pièces } \\
\text { - débris }-1 \text { pièce }\end{array}$ \\
\hline Bloc $n^{\circ} 4$ & $\begin{array}{l}\text { - mise en forme }-5 \text { pièces } \\
\text { - débitage de lames }-2 \text { pièces }\end{array}$ & $\begin{array}{l}\text { - nucléus - } 2 \text { pièces } \\
\text { - mise en forme }-1 \text { pièce } \\
\text { - débris }-2 \text { pièces }\end{array}$ \\
\hline Bloc $n^{\circ} 5$ & $\begin{array}{l}\text { - mise en forme }-1 \text { pièce } \\
\text { - débitage de lames - } 8 \text { pièces }\end{array}$ & $\begin{array}{l}\text { - nucléus }-1 \text { pièce } \\
\text { - débris - } 4 \text { pièces }\end{array}$ \\
\hline Bloc $n^{\circ} 6$ & $\begin{array}{l}\text { - débitage d'éclats }-1 \text { pièce } \\
\text { - ravivage de plan de frappe - } \\
1 \text { pièce }\end{array}$ & $\begin{array}{l}\text { - nucléus - } 1 \text { pièce } \\
\text { - débitage d'éclats - } 3 \text { pièces } \\
\text { - débris - } 1 \text { pièce }\end{array}$ \\
\hline Bloc $n^{\circ} 7$ & $\begin{array}{l}\text { - ravivages de surface debitée - } \\
1 \text { pièce } \\
\text { - débitage de lames - } 6 \text { pièces }\end{array}$ & - nucléus - 2 pièces \\
\hline
\end{tabular}

Les postes de débitage, aussi bien ceux dessinés par la planigraphie que ceux qui ont pu être reconstitués pour les remontages se distinguent les uns des autres par le degré de densité de silex et par le nombre de nucléus débités. Pour cette raison, ils ont été classés en deux groupes: les postes de débitage principaux qui fonctionnent pendant toute la durée du campement, et les postes temporaires de débitage situés, en règle générale, en bordure du campement (Bodu, Karlin, Ploux 1990 - p. 146). Les postes de débitage principaux portent les chiffres de 1 à 4 , les postes temporaires sont désignés par les lettres A et B (fig. 5-1,2). Quant aux relations chronologiques entre ces postes, tout porte à croire que les plus anciens, qui fonctionnaient en même temps, étaient les postes 1 et 2, à en juger par la présence de produits de débitage dans l'accumulation de silex. Si en revanche l'on devait admettre que les plus anciens étaient les postes 3 et 4 , l'accumulation aurait dû livrer au moins quelques vestiges isolés tirés du bloc 8 .

\subsection{2 - Tranchée 9}

Le matériel lithique mis au jour dans cette tranchée (fig. 6-1) appartient à différentes phases chronologiques d'occupation: phase paléolithique - ensembles mazoviens (fig. 6); phase mésolithique - culture janislawicienne et âge du bronze - culture trzcianicienne. 
Figure 6 - Nieborowa I, tranchée 9.

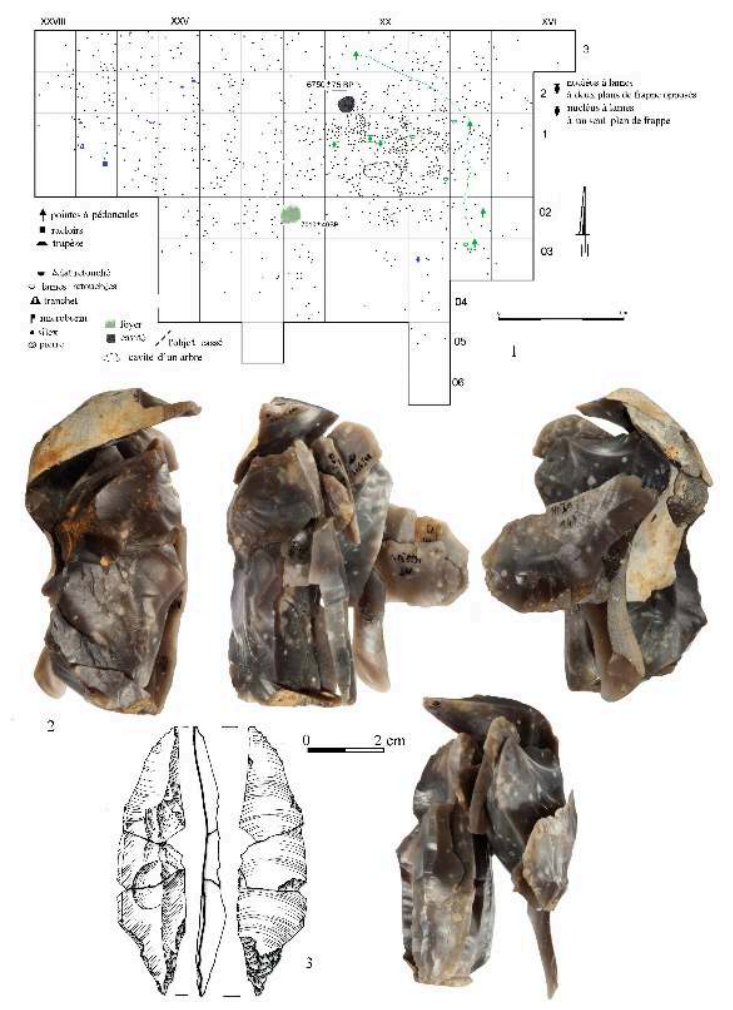

1 - plan de répartition des objets ; 2 - bloc mazovien en silex $n^{\circ} 1 ; 3$ - pointes à pédoncules (les objets du Paléolithique sont en vert, ceux du Mésolithique, en bleu).

Les vestiges archéologiques de la phase d'occupation mazovienne apparaissent sous forme d'une concentration lithique de $12 \mathrm{~m} 2$ où les silex sont assez régulièrement dispersés. Le campement constitue le vestige d'une occupation développée en deux temps.

On y a travaillé des nucléus laminaires à deux plans de frappe qui, comme l'indiquent les remontages, passaient par le cycle entier d'élaboration, depuis la préparation des deux plans de frappe et de la surface de débitage jusqu'à l'exploitation finale.

Les artefacts de la première étape d'utilisation ont été débarrassés et déposés autour du premier poste de débitage comme en témoigne la distribution des produits tirés du bloc 1 remonté (fig. 6-2; fig. 7-1). Ses différents éléments provenaient de la couche de surface ainsi que des tranchées 2 et 9 mais la plupart se trouvaient dans la tranchée 9. Le réseau de liaisons entre ces objets présente une configuration particulièrement difficile à démêler et se concentre autour de deux postes de débitage plus récents. Il est difficile d'imaginer que cette distribution circulaire restitue l'emplacement réel des silex, aussi sommes-nous amené à croire qu'à l'origine de tous ces aménagements postérieurs, existait une volonté de débarrasser les déchets de fabrication afin de faire de la place pour un futur poste de taille. A notre grand regret, tous les silex gisant sur le sol ayant été ramassés, il n'a été possible d'établir ni le nombre de postes de débitage ni leurs relations spatiales. 
Figure 7 - Nieborowa I, tranchée 9. Mazovienne. Plan de localisation des remontages lithiques

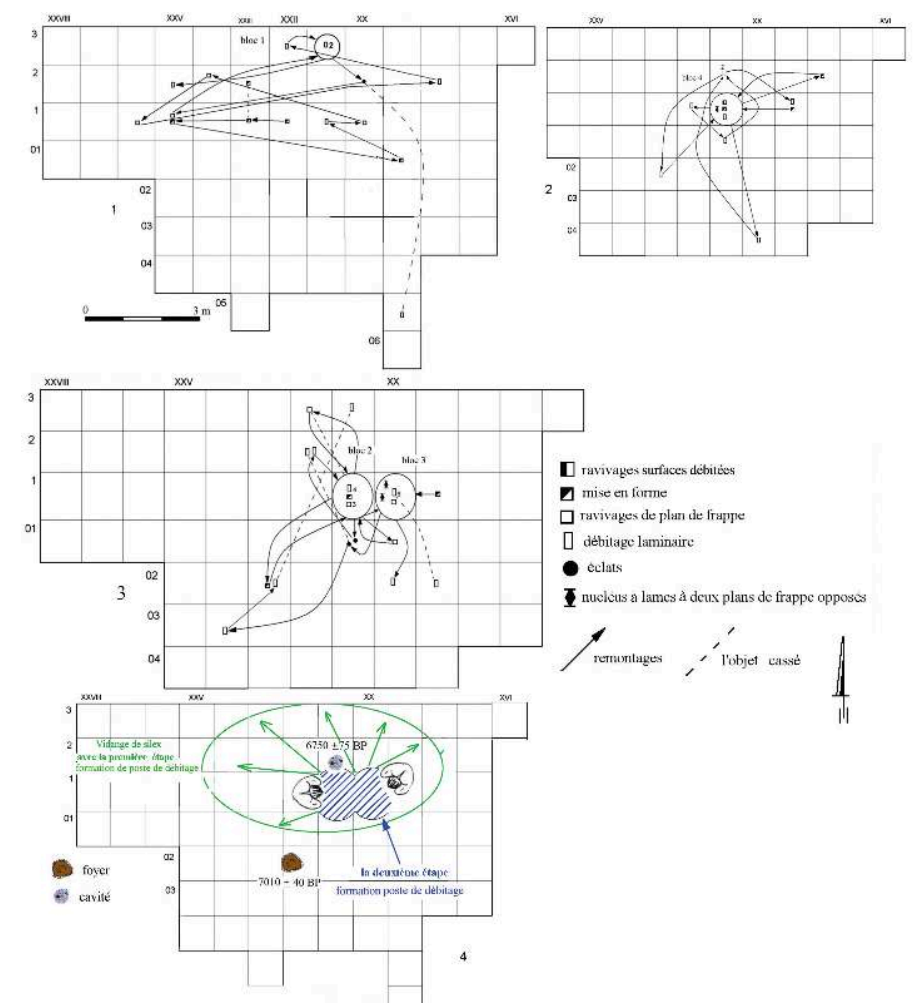

1 - bloc $n^{\circ} 1 ; 2-$ bloc $n^{\circ} 4 ; 3$ - blocs $n^{\circ} 2$ et $3 ; 4$ - plan de synthèse de l'organisation spatiale.

31 La seconde étape d'utilisation du lieu est marquée par la création de deux postes de débitages proches l'un de l'autre dont témoigne la dispersion des éléments tirés des blocs 2,3 et 4 (fig. 7,2-3). La localisation de ces deux postes les plus récents sur un terrain préalablement nettoyé constitue un argument de plus en faveur de la thèse de leur contemporanéité (fig. 7-4). Une configuration spatiale semblable a été observée au campement paléolithique final de Ślęza 11/12 (Bronowicki, Bobak 2003 - p. 24).

\section{2 - Occupation mésolithique, culture de Janislavice (industries classiques sans trapèzes)}

\subsection{1 - Tranchée 4 Secteur 1}

Le secteur I laisse apparaître deux concentrations distinctes de silex : la concentration A, avec des vestiges d'occupation attribués aux cultures de Janislawice et lusacienne, et un amoncellement d'artefacts désigné par la lettre $C$, contenant des ensembles mazoviens (culture swiderienne) (fig. 8). 
Figure 8 - Nieborowa I. Plan de répartition des silex en tranchée 4, secteur I (les objets du Paléolithique sont en vert, du Mésolithiques en bleu, ceux du Néolithique et de l'âge des métaux en rouge.

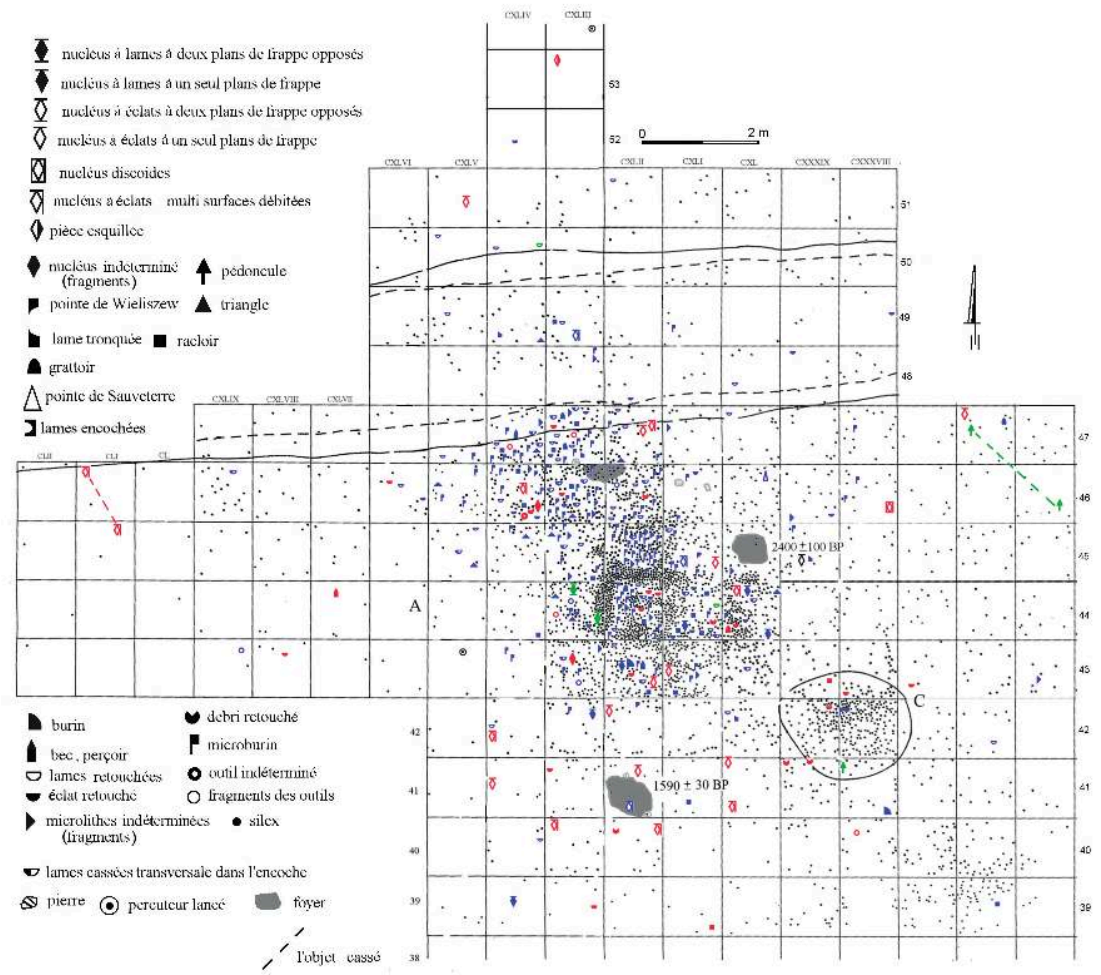

Les restes de l'occupation janislawicienne sont apparus sous forme d'une concentration de silex d'environ $25 \mathrm{~m} 2$, désignée par la lettre A. Elle contenait les nucléus, les éclats, les lames et les outils (tabl. 3). 
Tableau 3 - Liste des produits de silex janislavicienne de la tranchée 4 (secteur II et I) et la tranchée 7.

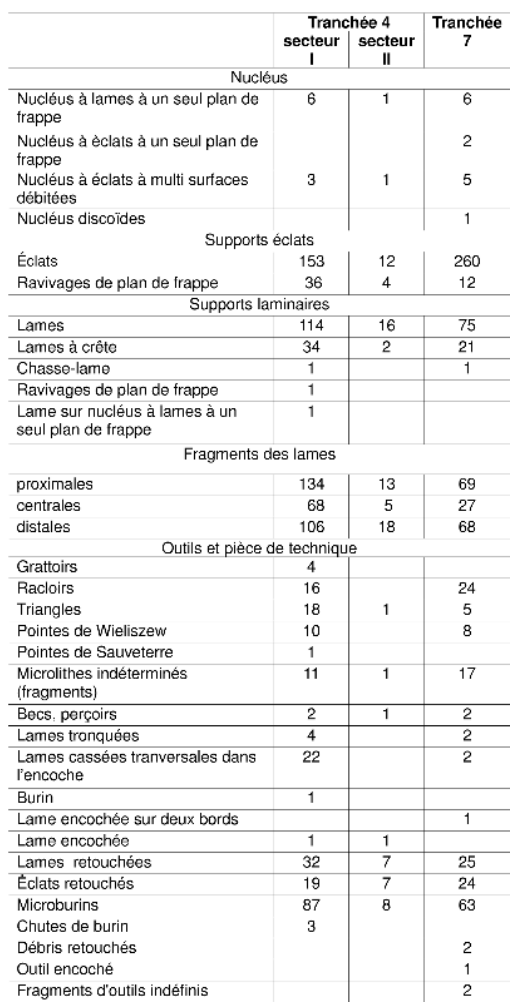

Tableau 4 - Nieborowa I, tranchée 4, secteur I, tranche 7. Culture de Janisławice. Décompte de l'outillage lithique.

\begin{tabular}{|c|c|c|c|c|c|c|}
\hline \multirow[b]{2}{*}{ Outils } & \multicolumn{3}{|c|}{$\begin{array}{c}\text { Tranchée } 4 \text {, secteur I } \\
\text { campement mésolithique }\end{array}$} & \multicolumn{3}{|c|}{$\begin{array}{c}\text { Tranchée } 7 \\
\text { campement mésolithique }\end{array}$} \\
\hline & $\begin{array}{c}\text { Territoire } \\
\text { domestique } \\
\text { du sud }\end{array}$ & $\begin{array}{l}\text { Poste de } \\
\text { débitage }\end{array}$ & $\begin{array}{c}\text { Territoire } \\
\text { domestique } \\
\text { du nord }\end{array}$ & $\begin{array}{c}\text { Territoire } \\
\text { domestique } \\
\text { du sud }\end{array}$ & $\begin{array}{l}\text { Poste de } \\
\text { débitage }\end{array}$ & $\begin{array}{c}\text { Territoire } \\
\text { domestique du } \\
\text { nord }\end{array}$ \\
\hline $\begin{array}{l}\text { Pointes de } \\
\text { Wieliszew }\end{array}$ & + & + & + & + & + & + \\
\hline Triangles & + & + & + & + & + & + \\
\hline $\begin{array}{l}\text { Lames } \\
\text { tronquées }\end{array}$ & + & - & + & + & - & - \\
\hline $\begin{array}{l}\text { Pointe de } \\
\text { Sauveterre }\end{array}$ & - & - & + & - & - & - \\
\hline $\begin{array}{l}\text { Lame } \\
\text { encochée }\end{array}$ & & + & & & & \\
\hline Racloirs & + & - & + & + & - & + \\
\hline Grattoirs & + & + & + & - & - & - \\
\hline Burins & + & - & - & - & - & - \\
\hline $\begin{array}{l}\text { Becs, } \\
\text { perçoirs }\end{array}$ & + & - & + & + & - & + \\
\hline $\begin{array}{l}\text { Lame } \\
\text { encochée } \\
\text { sur les deux } \\
\text { bords }\end{array}$ & - & - & - & + & - & - \\
\hline $\begin{array}{l}\text { Outils } \\
\text { encochés }\end{array}$ & - & - & - & - & - & + \\
\hline $\begin{array}{l}\text { Microlithes } \\
\text { indéterminés } \\
\text { (fragments) }\end{array}$ & + & + & + & + & + & + \\
\hline Mircoburins & + & + & + & + & + & + \\
\hline
\end{tabular}


L'essentiel des découvertes, en particulier de nombreuses lames, ont été mises au jour dans sa partie centrale (fig. 9-3). Deux accumulations, sud et nord, se dessinent nettement dans la distribution des outils, en bordure de la concentration. Elles concernent tout particulièrement les racloirs et les éclats retouchés qui n'apparaissent guère dans sa partie centrale. Les deux concentrations présentent un nombre d'outils et une composition typologique comparables (tabl. 4). Les microburins sont présents dans les deux concentrations mais aussi dans la partie centrale où ils forment deux accumulations distinctes.

Figure 9 - Nieborowa I, tranchée 4, secteur I. Culture janislavicienne.

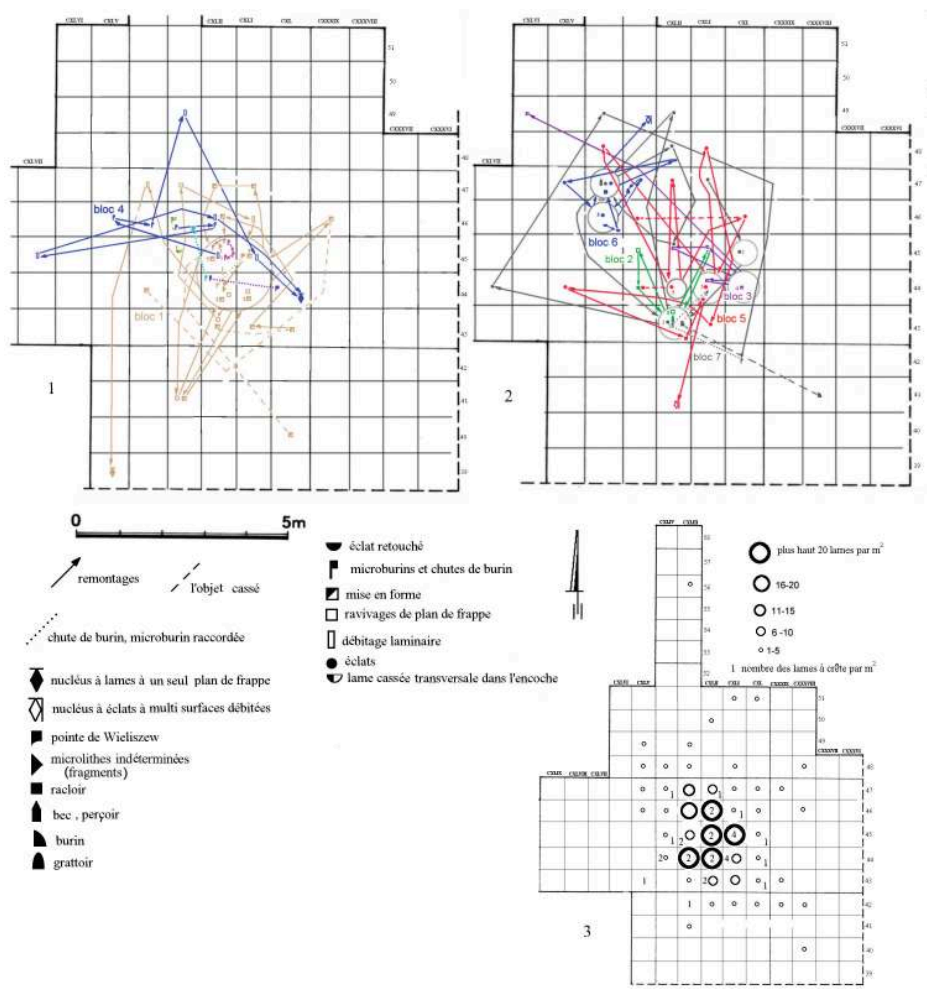

1-2 - plan de localisation des remontages lithiques ; 3 - nombre des lames par $\mathrm{m}^{2}$.

Les blocs remontés peuvent être divisés en deux catégories : les premiers illustrent la fabrication de microlithes (fig. 11-5 à 11) ainsi que la mise en forme et l'exploitation de nucléus à lames (fig. 10-1,2 ; fig.11-4) ou ravivages de plan de frappe (fig. 11-2,3), les seconds, le débitage d'éclats (fig.10-3,4; fig.11-1; fig. 12- 1 à 3). 
Figure 10 - Nieborowa I, tranchée 4, secteur I. Culture janislavicienne.

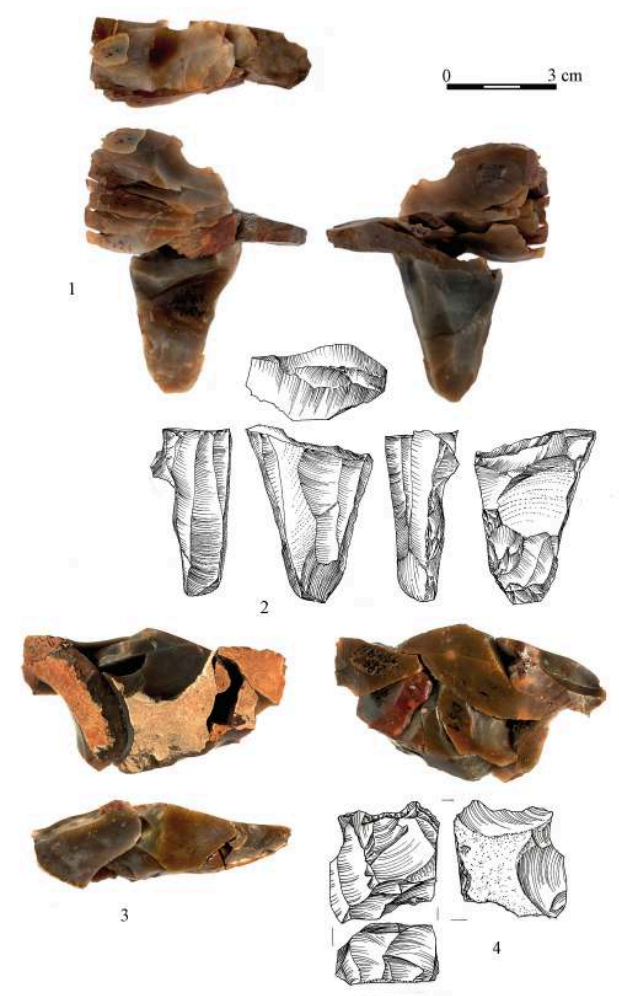

1 - bloc en silex $n^{\circ} 1 ; 2$ - nucléus avec bloc $n^{\circ} 1 ; 3$ - bloc en silex $n^{\circ} 6 ; 4$ - nucléus avec bloc $n^{\circ} 6$.

Figure 11 - Nieborowa I, tranchée 4, secteur I. Culture janislavicienne.

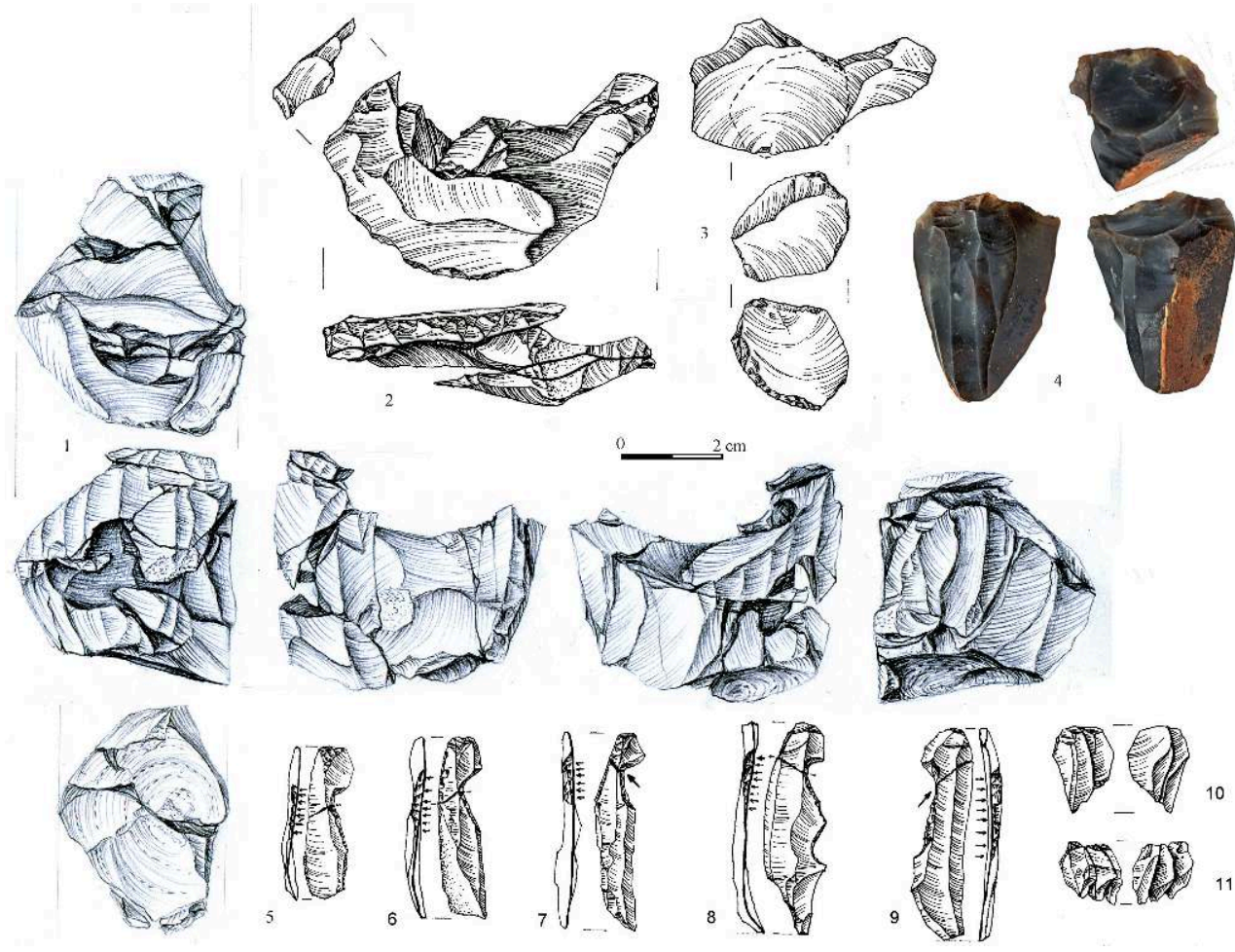

1 - bloc en silex $n^{\circ} 5 ; 2$ - remontage des ravivages de plan de frappe ; 3 - racloir ; 4 - nucléus à lames à un seul plan de frappe ; 5-9- remontages des pointes de Wieliszew ; 10-11 - remontages des microburins. 
Les liaisons de remontage issus de la fabrication de microlithes se font à l'intérieur de la concentration des artefacts et entre ceux-ci et les concentrations sud et nord. Il n'y a toutefois, aucune liaison reliant directement ces deux concentrations (fig. 9-1).

Le débitage d'éclats dessine un réseau à deux endroits distincts (fig. 9-2): le premier, à côté du foyer où ont été travaillés les blocs 6 et 7 (fig. 9-2), et le second, en bordure de la concentration centrale où se trouvaient les artefacs débités à partir du bloc 5. Cette répartition assez lisible entre deux zones de débitage d'éclats est obscurcie par la dispersion des artefacts du bloc 7. La distribution spatiale de ces éléments montre bien que ce dernier bloc a été travaillé dans les deux zones (fig. 9-2).

À l'intérieur de la concentration de silex attribuée à la culture de Janislawice on distingue nettement trois structures : deux amoncellements de silex - sud et nord - et une concentration contenant le plus grand nombre d'objets. Cette répartition correspond à diverses aires d'activités. La place centrale était occupée par le poste de débitage principal (atelier principal), tandis que les unités sud et nord constituaient des aires d'activités domestiques (Boroń 2004 - p. 12-14).

\section{Poste de débitage (atelier) principal}

C'est sur ce poste de débitage qu'ont eu lieu la mise en forme et l'exploitation de nucléus à lames. Le diagramme de densité de lames, de lames de crête et de lignes de remontages a permis d'identifier à l'intérieur de cette unité deux zones distinctes de débitage de lames secondairement utilisées dans la fabrication de microlithes. Les vestiges de cette activité apparaissent sous forme de deux amoncellements de microburins situés à proximité des lieux de débitage de lames. Ce poste fut sans doute le lieu principal de fabrication de microlithes, ce que semble confirmer le bloc 1 (fig. 10-1) sur lequel il a été possible d'associer une pointe de Wieliszew et deux microburins (fig. 11,7-10).

4 Les lames brutes étaient évacuées pour être travaillées dans les zones nord et sud, ce dont témoigne la distribution des produits issus du bloc 4 (fig. 9-1).

2 Ce poste a aussi été un lieu de débitage d'éclats, comme le montrent les vestiges déposés postérieurement. L'exploitation secondaire d'un nucléus, à l'origine à lames (bloc 5) (fig. 11-1), valide l'hypothèse d'une accumulation d'artefacts en deux temps, très vraisemblablement liée au changement de mode d'exploitation du silex dans ce poste (débitage de lames puis débitage d'éclats).

\section{Aires d'activités domestiques}

Elles sont situées au sud et au nord de l'atelier principal. L'outillage y est assez régulièrement réparti, la concentration nord comporte en outre un foyer. Il n'existe toutefois aucun indice fiable permettant de constater que les aires d'activités étaient spécialisées dans le débitage laminaire, ce que semble pourtant suggérer la présence de lames déposées à ces endroits. Par ailleurs, les remontages des blocs 6 et 7 (fig. 9-2) prouvent que les vestiges d'exploitation d'éclats dans la concentration nord font exception et ceux qui s'y trouvent présentent un caractère bien spécifique. L'absence de dépôt particulier d'artefacts tirés du bloc 7 (fig.12) indique que le débitage se faisait par étapes.

\subsection{2 - Tranchée 4 secteur II}

- Matériel attribué à la culture janislavicienne 
Le dépôt du matériel janislawicien jouxtait par le nord les postes de débitage attribués à l' occupation mazovienne. Il couvrait une superficie d'environ $10 \mathrm{~m} 2$ (fig. 2). Cette zone n'a guère livré de d'objets témoignant d'un intense travail du silex. Deux blocs ont pu être remontés (fig. 13-2,7) dont les fragments (lames retouchées) provenaient de la concentration janislawicienne de la zone I (fig.13-1). Le petit nombre d'artefacts - (à peine deux microlithes, fig. 13-8), l'absence de concentration véritable, de même que les lignes de remontage reliant les deux concentrations de la zone I et II semblent indiquer qu'il s'agissait d'un espace satellite utilisé durant le fonctionnement du campement principal dans la zone I. Des relations spatiales semblables entre deux concentrations, séparées mais contemporaines, ont été observées sur le site azilien des Varennes (Pasty, Alix, Pelletier, Combes 2011, fig. 12,13) et sur le site magdalénien de Verberie (Audouze, Cahen, Keeley, Schmider 1981 - p. 135).

Figure 12 - Nieborowa I, tranchée 4, secteur I. Culture janislavicienne.

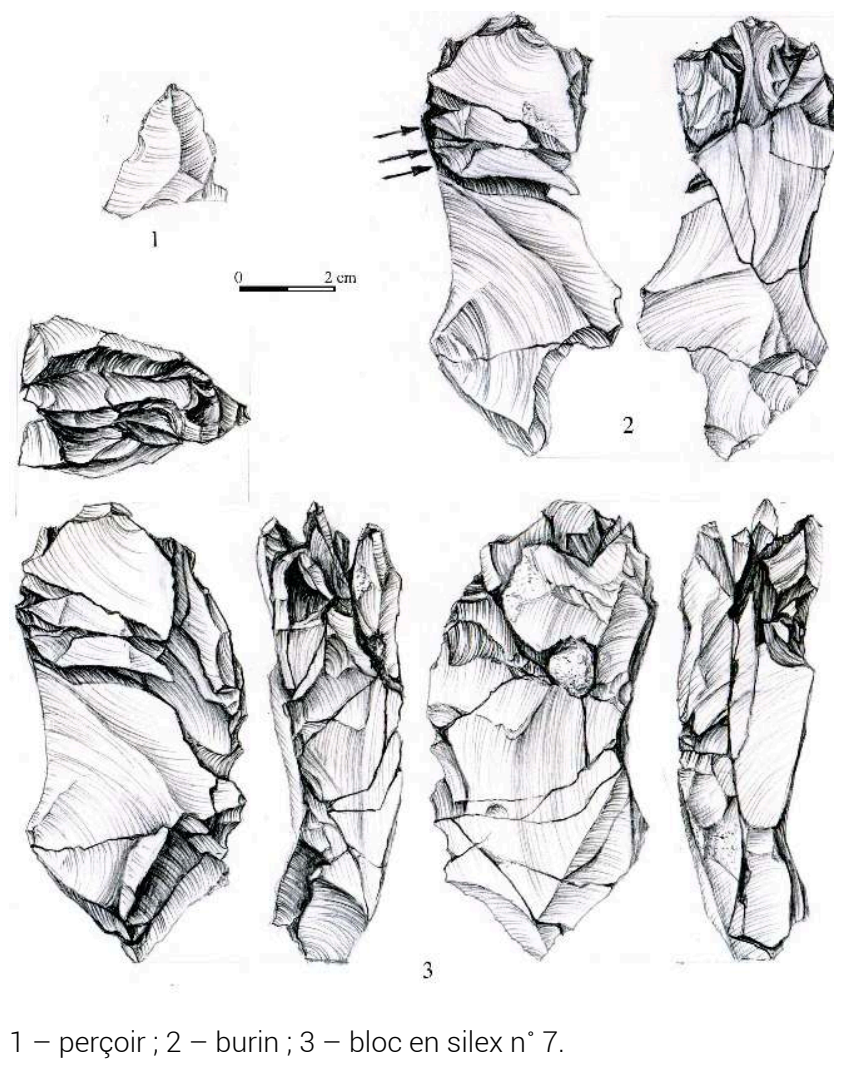


Figure 13 - Nieborowa I, tranchée 4, secteur II. Culture Janislavicienne
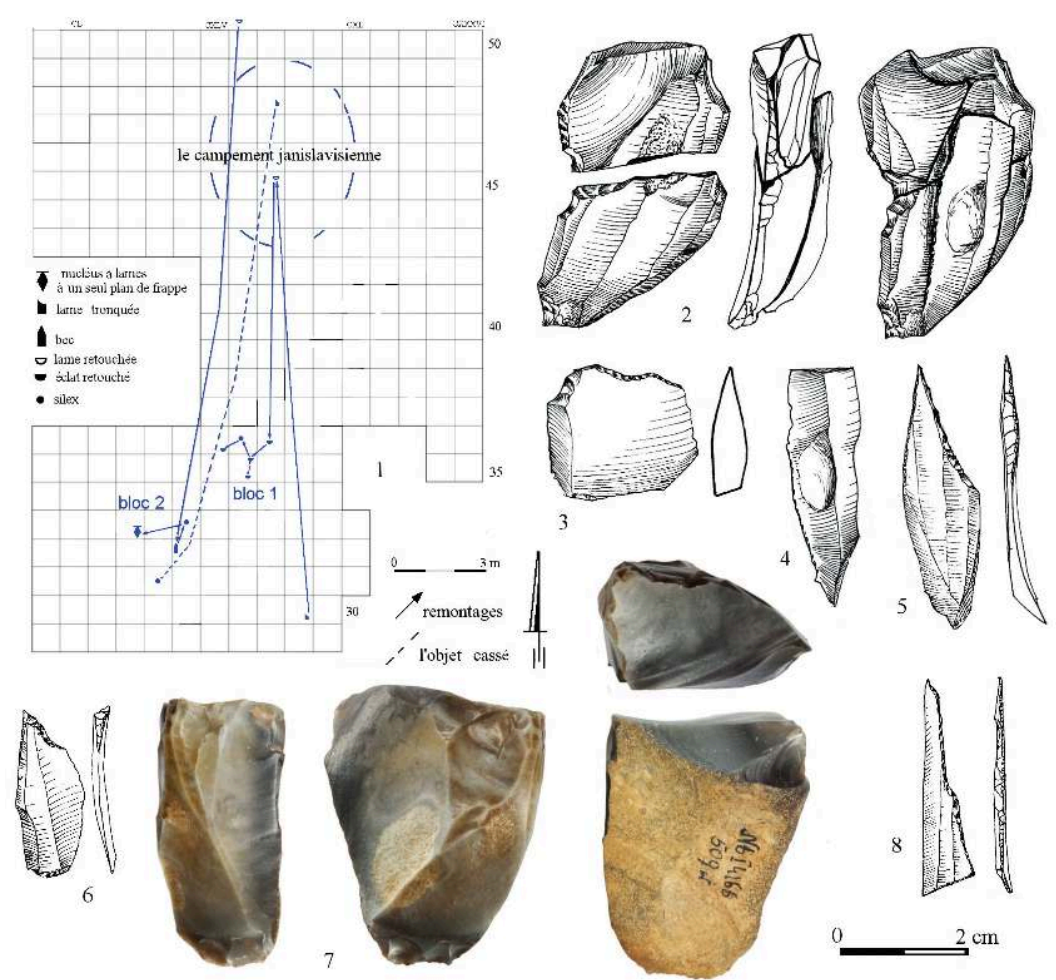

Plan de localisation des remontages lithiques entre secteur I et II ; 2 - bloc en silex $n^{\circ} 1 ; 3-5$ - les piéces de remontage en bloc $n^{\circ} 1 ; 6$ - perçoir avec bloc $n^{\circ} 2 ; 7$ - nucléus à lames à un seul plan de frappe avec bloc $n^{\circ} 2 ; 8$-triangle. 
Figure 14 - Nieborowa I, tranchée 7. Plan de répartition des objets. Les objects du Mésolithique sont en bleu.

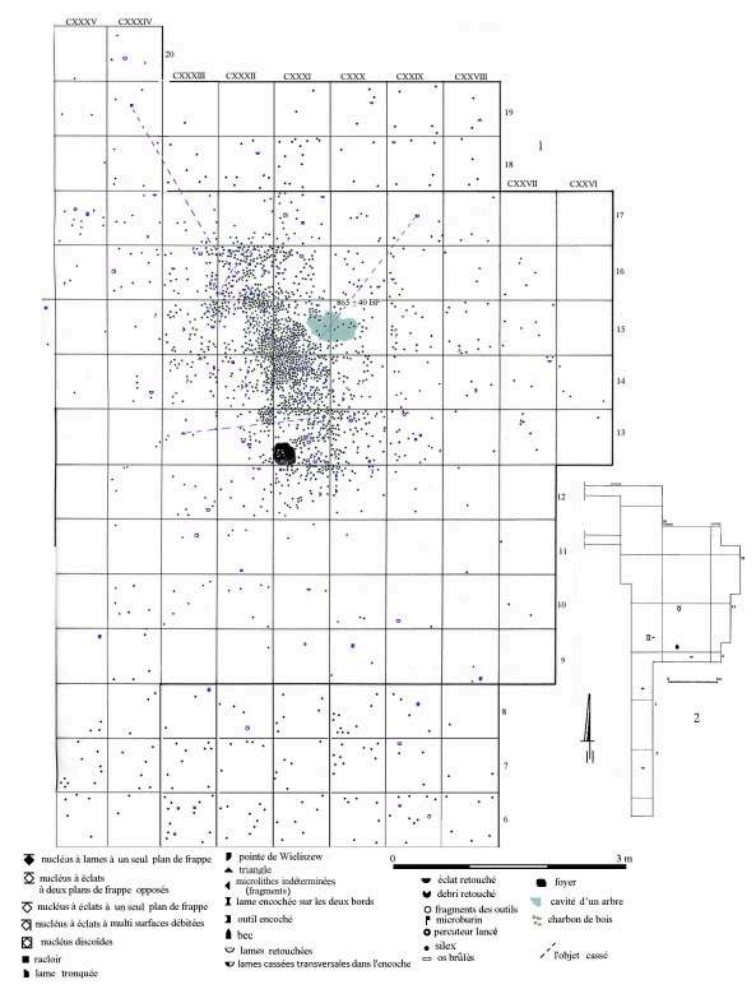

- Structures

Deux foyers ont été découverts dans le secteur II. L'analyse des charbons de bois prélevés dans l'un d'entre eux a permis d'obtenir la date ${ }^{14} \mathrm{C}$ de $2185 \pm 30 \mathrm{BP}$. Le second foyer, situé dans les carrés 31/32 (CXLVI/CXLVII), présente un intérêt majeur à cause de son emplacement car il se trouve entre la concentration des artefacts attribués à la culture janislawicienne et le poste de débitage appartenant à l'occupation mazovienne. Ce foyer a livré un lot d'objets mazoviens brûlés (fig. 2). Les relations stratigraphiques entre le foyer et le dépôt de matériel lithique - mazovien et janislawicien - peuvent être établies d'après l'analyse des données fournies par les remontages. Il faut exclure d'emblée tout rapport temporel entre le foyer et la première étape d'accumulation du matériel mazovien débarrassé et entassé à environ $10 \mathrm{~m}$ du foyer et dans lequel il n'y avait point de silex brûlés. Ceci montre que le foyer fut postérieur à la première occupation mazovienne et qu'il doit être lié à la deuxième étape d'accumulation du matériel lithique ou à l'occupation janislawicienne.

\subsection{3 - Tranchée 7}

La fouille de la tranchée 7 a mis au jour une concentration d'environ $20 \mathrm{~m} 2$ (fig. 14-1) d'artefacts en silex attribuables à la culture janislawicienne. La majeure partie d'entre eux a été observée au centre de cette concentration. Le diagramme de densité de lames montre bien qu'elles sont plus nombreuses au centre et qu'au fur et en mesure que l'on s'éloigne, leur nombre diminue très sensiblement (fig. 15-1). Les éclats sont en revanche assez régulièrement dispersés sur une surface beaucoup plus grande qui dépasse le centre même de la concentration (fig. 15-2). La plus importante accumulation de silex a livré surtout des microlithes et des microburins. Dans les 
parties nord et sud, outre les mircolithes, ont été également découverts des outils sur éclat et sur lame. Le tableau 4 (données quantitatives des outils dans les concentrations de Janisławice) montre que dans les parties nord et sud de la concentration apparaissent les mêmes formes d'outils (du point de vue typologique).

Figure 15 - Nieborowa I, tranchée 7. Culture janislavicienne

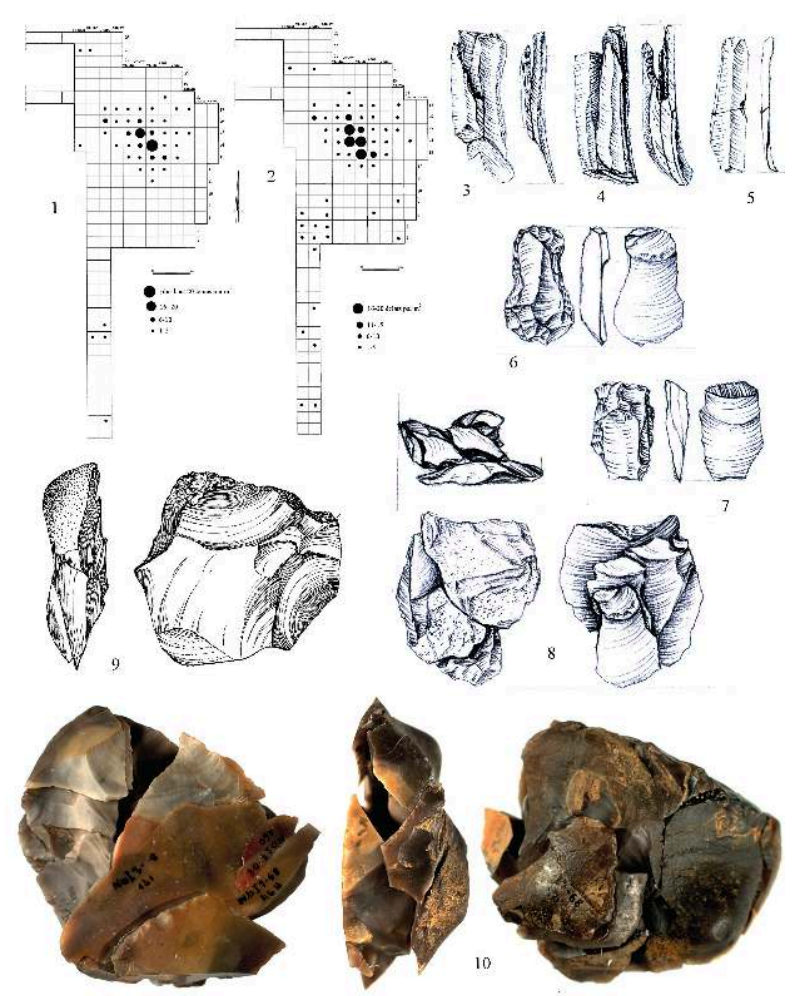

1 - nombre des lames par $\mathrm{m}^{2} ; 2$ - nombre d'éclats par $\mathrm{m}^{2} ; 3-4$ - remontages des microlithes ; 5 lame cassée transversale dans l'encoche ; 6 - lame encochée sur les deux bords (bloc en silex $n^{\circ} 9$ ) ; 7 - racloir (bloc en silex $n^{\circ} 9$ ) ; 8 - bloc en silex $n^{\circ} 9 ; 9$ - nucléus résiduel avec bloc $n^{\circ} 6 ; 10$ - bloc en silex $n^{\circ} 6$

L'analyse des liaisons entre les artefacts de dix blocs remontés montre que les lignes relient le plus souvent la partie centrale de la concentration à la zone nord ou à la zone sud. Les lignes reliant ces deux zones entre elles sont très rares (fig. 16-1,2).

Les données fournies par la distribution des outils lithiques, les diagrammes de densité des lames et des éclats et par les remontages ont permis de mettre en évidence trois unités spatiales, tout comme dans la concentration janislawicienne de la tranchée 4 , zone I.

$\mathrm{Au}$ centre de cette concentration, se trouve un poste de débitage domestique où l'on travaillait principalement des nucléus laminaires et où l'on fabriquait des microlithes (fig. 15-3 à 5 ; fig. 16-1). La distribution des artefacts tirés des blocs 1, 2, 3 et 4, ainsi que des lames, permet de supposer que dans cet atelier domestique, le débitage laminaire s'effectuait à deux endroits distincts. 
Figure 16 - Nieborowa I, tranchée 7. Culture janislavicienne

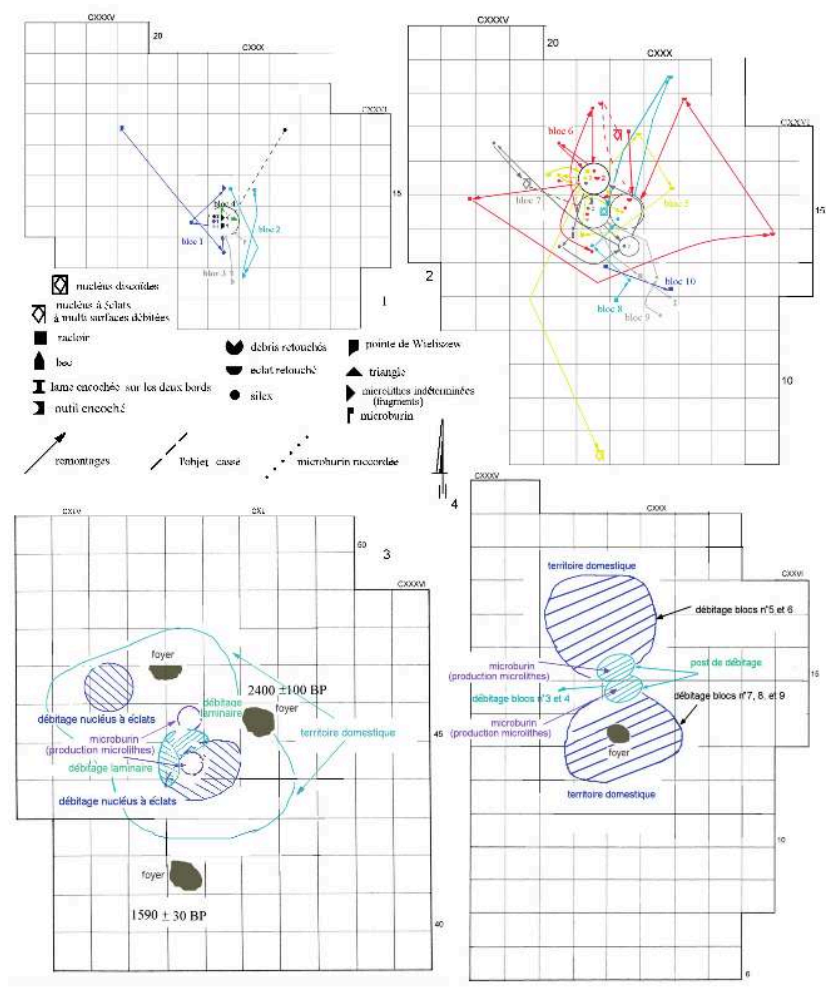

1-2 - plan de localisation des remontages lithiques ; 3 - tranchée 4, secteur I : plan de synthèse de l'organisation spatiale ; 4 - tranchée 7 : plan de synthèse de l'organisation spatiale.

Les zones contiguës au poste de débitage des côtés nord et sud ont pu être définies comme aires d'activités domestiques. La nature et l'importance de ces zones sont déterminées par la présence, dans l'une d'entre elles, d'un foyer identifié à partir de charbons de bois et de menus ossements d'animaux brûlés (fig. 14).

L'activité économique propre à ces deux zones est liée à l'exploitation et à la fabrication d'outillage d'éclats, à la fabrication de microlithes à partir de lames apportées de l'atelier et du débitage d'éclats. L'importance de la superficie de la zone de présence des éclats tirés des blocs 6 (fig. 15-10), 7 et 9 (fig. 15-6 à 8) permet de croire que le débitage de nucléus se faisait ad hoc, en fonction de la demande en supports. Il est possible d'en déduire que les nucléus étaient travaillés par étapes. Ce système d'exploitation rend difficile l'identification précise des lieux de débitage.

Puisque les deux unités présentent une structure spatiale semblable, il est légitime de penser que la partie nord de la concentration comporte, elle aussi, un foyer. Or, aucune trace de charbon de bois n'y a été découverte.

\subsection{4 - Tranchée 9}

Malgré le petit nombre de vestiges lithiques, cette occupation présente une configuration spatiale très compliquée du point de vue fonctionnel. Outre les outils qui se trouvent dans la partie ouest de la tranchée, deux structures, un foyer et une fosse situés dans la partie est de la tranchée, font partie de cette unité.

L'absence de supports laminaires, de nucléus et d'outils d'usage quotidien (grattoirs, racloirs) d'une part et la présence de structures domestiques du genre foyer et fosse 
d'autre part, semblent prouver que les vestiges mésolithiques de cette tranchée ne représentent qu'une partie du campement qui n'a pas été exploré jusqu'au bout.

\section{3 - Occupation postjanislavicienne}

La tranchée 2 de $278 \mathrm{~m} 2$ de superficie a fait l'objet d'explorations pendant les campagnes 1964-1965. L'analyse spatiale a concerné la partie occidentale de la tranchée où se trouvait une concentration mésolithique de silex (fig. 17) qui s'étend sur une surface d'environ $25 \mathrm{~m}^{2}$. Elle se caractérise par une distribution assez régulière d'outils et de silex, avec une concentration plus dense de silex (de 30 à 40 par m2) dans sa partie centrale (XL - XXXVIII, 3-4) (tabl. 5) (fig. 17). Quant aux outils, leur distribution est notée sur un territoire beaucoup plus grand, plus de $45 \mathrm{~m}^{2}$. Mis au jour dans le carré 4 , les menus ossements brûlés d'animaux semblent indiquer l'emplacement du foyer.

Tableau 5 - Liste des produits de silex postjanislavicienne de la tranchée 2 et 3.

\begin{tabular}{|c|c|c|}
\hline & Tranchée 2 & Tranchée 3 \\
\hline \multicolumn{3}{|c|}{ Nucléus } \\
\hline $\begin{array}{l}\text { Nucléus à lames à un seul plans } \\
\text { de frappe }\end{array}$ & 1 & \\
\hline $\begin{array}{l}\text { Nucléus à èclats à un seul plans } \\
\text { de frappe }\end{array}$ & 5 & \\
\hline $\begin{array}{l}\text { Nucléus à èclats à multi surfaces } \\
\text { débitées }\end{array}$ & 10 & \\
\hline Nucléus indéterminé (fragments) & 2 & \\
\hline \multicolumn{3}{|c|}{ Supports éclats } \\
\hline Eclats & 294 & $90^{*}$ \\
\hline Ravivages de plan de frappe & 7 & \\
\hline \multicolumn{3}{|c|}{ Supports laminaires } \\
\hline Lames & 19 & \\
\hline Lames à crête & 5 & 1 \\
\hline \multicolumn{3}{|c|}{ Fragments de lames } \\
\hline proximale & 17 & 2 \\
\hline centrale & 8 & 2 \\
\hline distale & 18 & 2 \\
\hline \multicolumn{3}{|c|}{ Outils et pièces de technique } \\
\hline Grattoirs & 11 & \\
\hline Racloir & 77 & 6 \\
\hline Trapèzes & 5 & 2 \\
\hline Becs & 6 & \\
\hline Lames tronquées & 8 & \\
\hline $\begin{array}{l}\text { Lames cassées tranversale dans } \\
\text { l'encoche }\end{array}$ & 5 & \\
\hline Burins & 2 & \\
\hline Outils mixtes & 3 & \\
\hline Lames avec retouches continues & 8 & \\
\hline Lames encochées & 1 & \\
\hline Lames retouchées & 29 & 4 \\
\hline Eclats retouchés & 45 & 4 \\
\hline Denticulés & 1 & \\
\hline Microburin & 9 & \\
\hline Chutes de burin & 1 & \\
\hline Débris retouchés & 4 & \\
\hline Fragments d'outils indéfinis & 25 & \\
\hline
\end{tabular}


Figure 17 - Nieborowa I, tranchée 2. Plan de répartition des objets.

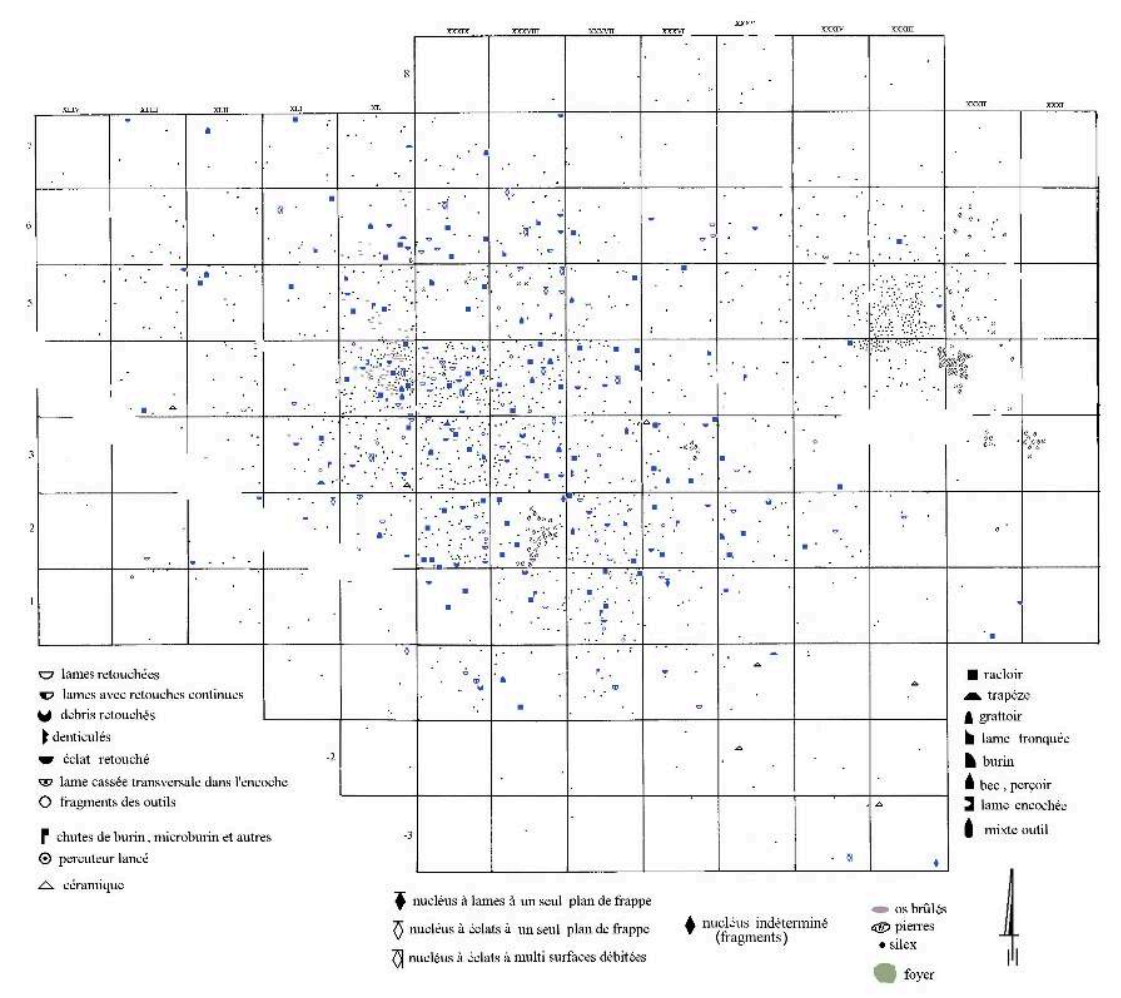

57 Les lignes de remontage d'artefacts forment un réseau qui se situe dans la partie nord de l'empierrement, autour du foyer, en cercle de 2-3 m de diamètre (fig. 18). Le réseau est beaucoup moins dense autour d'une concentration de pierres calcinées dans la partie sud, ce qui résulte vraisemblablement de l'absence de remontages plutôt que de l'activité économique moins intense. Les lignes de remontage présentes dans les deux parties de la concentration de silex (nord et sud) sont rares. L'emplacement d'outils (burins, becs - fig. 19-3) et de déchets de fabrication d'outils (chutes de burin, microburins - fig. 19-4) concentrés autour du foyer dans la partie nord de l'empierrement semble indiquer non seulement le lieu de fabrication d'outils mais aussi celui de leur exploitation.

Il convient toutefois de signaler l'absence d'ateliers de débitage de silex. En effet, les supports faisant partie des blocs remontés ne formaient pas de concentrations nettement délimitées mais étaient dispersés sur une assez grande surface (fig. 18). C'est la raison pour laquelle nous sommes dans l'impossibilité d'indiquer avec précision les lieux de débitage, même pour tel ou tel autre nucléus isolé.

59 Les nodules utilisés pour produire des nucléus à éclats mesuraient, pour la plupart, environ 60-70 mm (fig. 19-1), et aucun nucléus à lames, à l'exception d'un spécimen, n'est probablement dû à une transformation sur nucléus à éclats (fig. 19-2).

La présence des deux réseaux distincts que forment les lignes de remontage d'artefacts prouve que ce vaste espace empierré correspond à deux unités spatiales, chacune avec un foyer central. L'espace autour des deux foyers comporte différentes aires d'activités économiques : débitage de silex, fabrication et exploitation d'outils. Les deux structures se caractérisent par des lots d'outils similaires du point de vue typologique, à l'exception des trapèzes qui n'apparaissent que dans la partie nord de la concentration (fig. 20). 


\subsection{1 - Tranchée 3}

61 La distribution spatiale du matériel lithique est assez régulière sur l'ensemble de la superficie de la tranchée, sans zones de concentration (fig. $21: 1$ ).

62 L'analyse de la distribution des outils mésolithiques fait apparaître deux dépôts distincts. Le premier contient un outillage sur éclats, le second des outils laminaires (fig. 21-1).

63 Au sein du premier dépôt, un bloc a été remonté avec des éléments ne provenant que de deux groupes distincts: le groupe de racloirs et celui d'éclats (fig. 21-2,3). Cette situation n'est pas habituelle, les éléments des blocs composés étant d'habitude dispersés sur des surfaces plus vastes (fig.7-2,3;9-1,2;18).

64 La concentration de racloirs indique l'endroit de leur exploitation ou de leur fabrication car il est difficile d'imaginer qu'ils aient pu être rejetés pour former cette accumulation.

65 Étant donné qu'il y a une dispersion différente des outils laminaires et de l'outillage sur éclats, il est possible de présumer qu'il s'agit de deux zones distinctes propres à l'exécution des travaux domestiques à l'aide d' ensembles d'outils concrets comme c'est le cas du site magdalénien Cepoy (Wenzel, Jagu 2010, fig. 11 - p. 80).

\section{2 - Interprétation}

\section{1 - Occupation paléolithique}

\subsection{1 - Campements mazoviens}

Les campements mazoviens se distinguent par l'organisation du travail du silex qui s'effectue dans des ateliers (postes de débitage) spécialisés plus particulièrement dans la fabrication de lames. A Nieborowa I, les ateliers ont été localisés dans les tranchées 4 et 9. Les vestiges archéologiques permettent de constater qu'à ces deux endroits l'accumulation du matériel lithique s'est opérée en deux temps. On a pu noter que les déchets de fabrication correspondant à la première phase d'occupation avaient été débarrassés, mais aussi que le déblayage du lieu se faisait de différentes manières. Ainsi, dans la tranchée 4 , les pièces déposées à un endroit avaient été transportées et entassées à un autre endroit distant d'environ $10 \mathrm{~m}$ du dépôt primaire (fig. 5-1,2), tandis que dans la tranchée 9 , le déblayage du poste se faisait systématiquement et les artefacts étaient déposés autour du lieu de débitage (fig. 7-4). Le déblayage systématique de déchets accumulés dans des ateliers doit être considéré comme une activité cyclique dans les campements qui ont connu plusieurs phases d'occupation (Bodu, Karlin, Ploux 1990 - p. 146). 
Figure 18 - Nieborowa I, tranchée 2. Mésolithique. Plan de localisation des remontages lithiques.

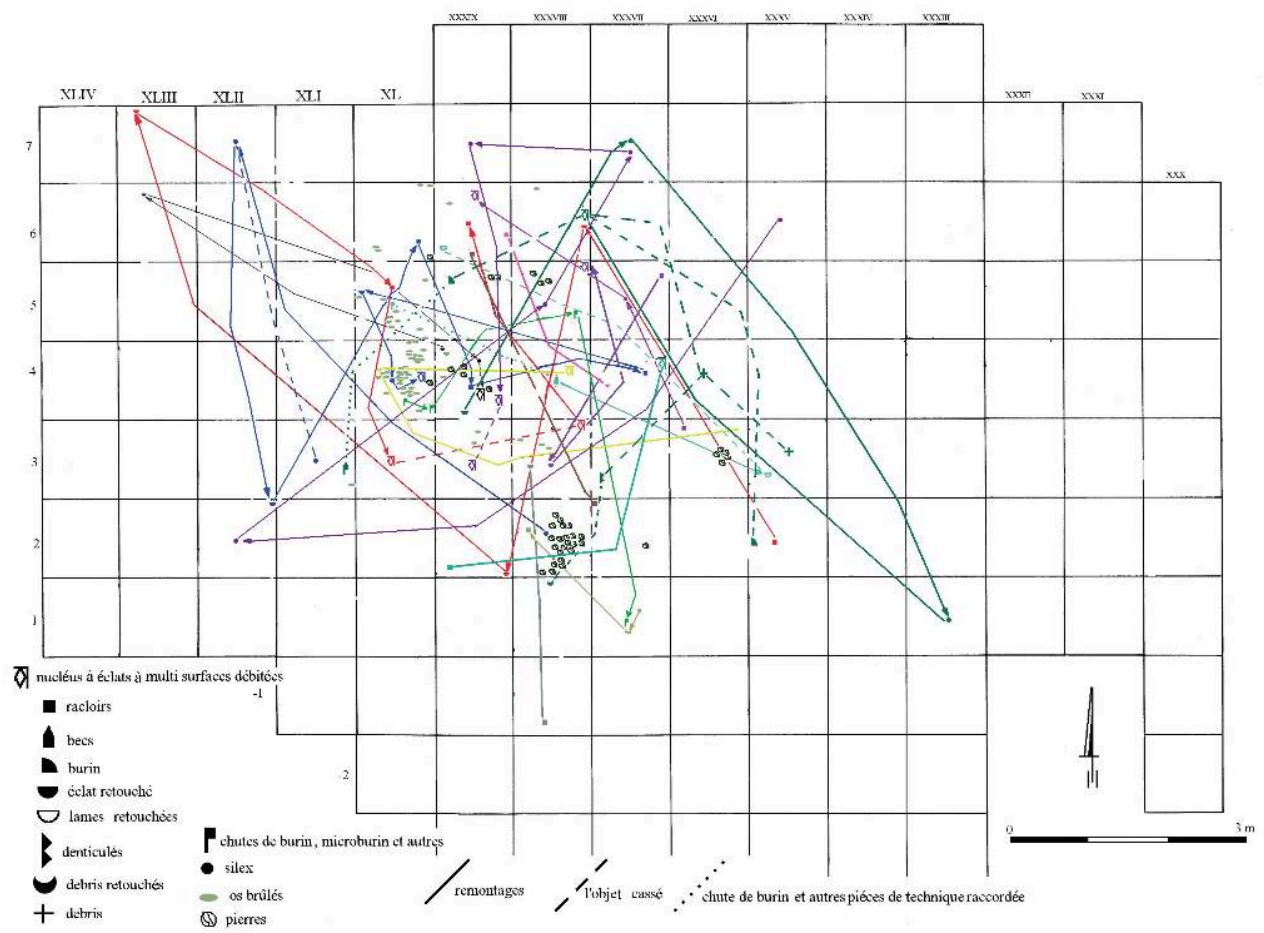

Les deux tranchées ayant livré un matériel lithique (outils) très modeste et sans concentrations évidentes, il est impossible d'identifier dans cette zone de véritables aires d'activités domestiques (Keeley 1991 - p. 266-267).

Dans la tranchée 4 les outils étaient dispersés autour des postes de débitage du silex brut. Il est à noter que ceci concerne en particulier les pointes à pédoncule dont l'une se trouvait dans l'amoncellement de silex, ce qui constitue vraisemblablement un indice permettant de penser que la fabrication de celles-ci et sans doute aussi la réparation d'armes se faisaient dans des ateliers et non pas autour des foyers (Cahen, Karlin, Keeley, Van Noten 1980 - p. 223 ; Carr 1991 - p. 244). 
Figure 19 - Nieborowa I, tranchée 2. Mésolithique.

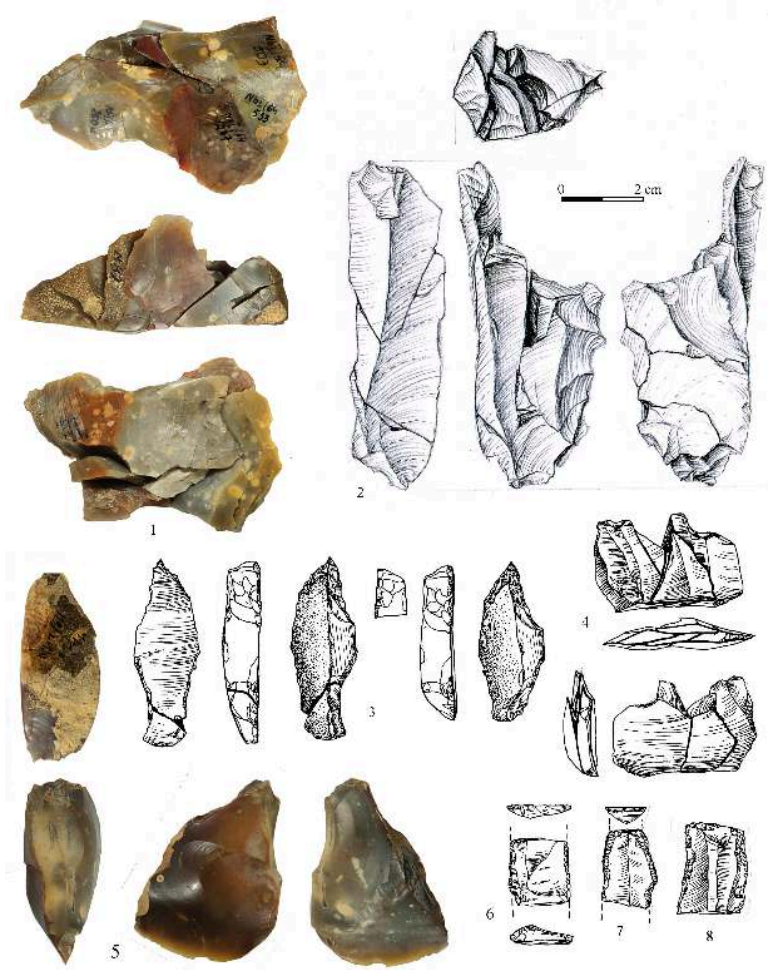

1 - bloc en silex ; 2 - bloc en silex ; 3 - remontage perçoir avec de la pièce de technique ; 4 remontages des microburins ; 5 - nucléus à lames à un seul plan de frappe ; 6-8 - lames avec retouches continues.

Pendant le fonctionnement des campements, dans chacun d'entre eux ont été mis en place deux postes de débitage distincts mais contemporains, situés à quelques mètres l'un de l'autre (tranchée 4, fig. 5-2) ou côte à côte (tranchée 9, fig. 7-4). Ces différences dans l'aménagement de l'espace peuvent correspondre à deux types de campements. Le premier où deux familles travaillent sur deux territoires distincts et le second où deux tailleurs de pierre assis l'un à côté de l'autre exploitent le silex. Les lames débitées sont soit transformées en pointes à pédoncule soit stockées pour être utilisées ensuite par des groupes de chasseurs. 
Figure 20 - Nieborowa I, tranchée 2. Plan de synthèse de l'organisation spatiale.

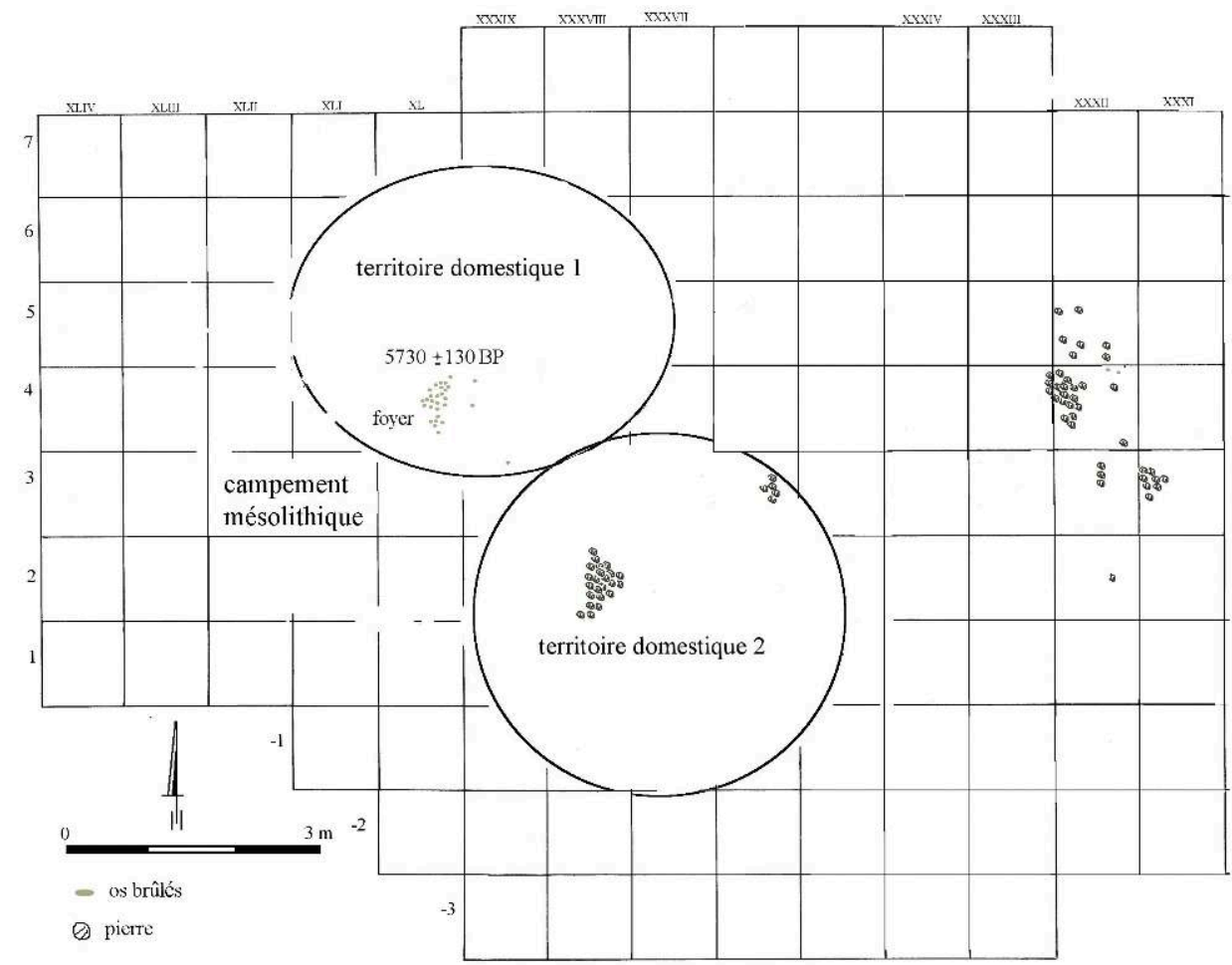

\section{2 - Occupation mésolithique}

\subsection{1 - Campements janislaviciens}

Les épisodes d'occupation janislavicienne dont les vestiges ont été mis au jour dans les tranchées 4 et 7 à Nieborowa I présentent un modèle semblable d'organisation de l'espace, caractérisé par la présence de deux unités spatiales situées sur l'axe nord-sud. Celles-ci comportent un poste de débitage domestique commun, en position centrale et, au sud et au nord de l'atelier, des aires d'activités domestiques (fig. 16-3,4). 
Figure 21 - Nieborowa I, tranchée 3.

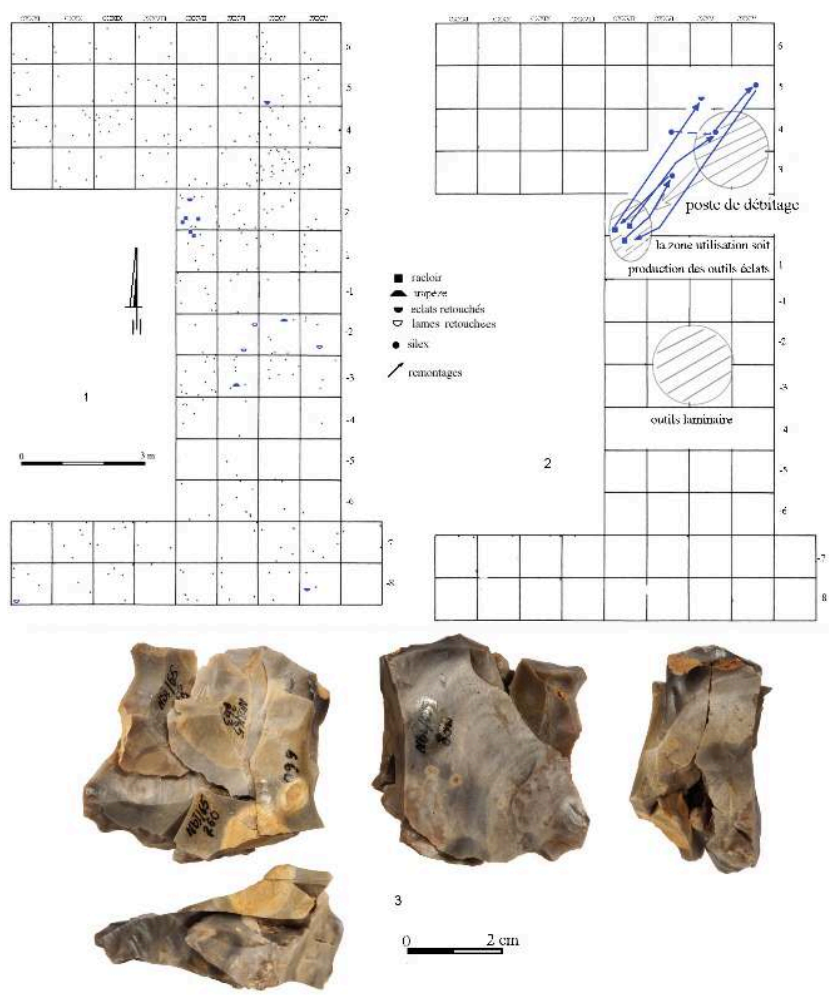

1 - plan de répartition des objets ; 2 - plan de synthèse de l'organisation spatiale du campement mésolithique ; 3 - bloc en silex.

71 L'atelier, bien délimité en surface, était le lieu de débitage de nucléus à lames (principale activité), mais aussi le lieu primaire de fabrication de microlithes. Deux concentrations distinctes de microburins découvertes à l'intérieur de l'atelier, vestiges de la dernière étape de fabrication d'outils (microlithes), semblent témoigner de la continuité du processus technologique mais aussi de l'existence de deux emplacements de débitage de nucléus à lames très proches l'un de l'autre.

Les aires d'activités domestiques situées dans la partie sud et nord étaient des lieux d'exploitation, de réparation et de fabrication supplémentaire de microlithes, ce dont témoignent les microburins et les outils sur éclats gisant à cet endroit.

Il reste la question de déterminer le rapport chronologique entre ces deux unités. Les sites de la culture de Maglemose semblent présenter de ce point de vue quelques analogies. O. Grön (1987 - p. $79 ; 2003$ - p. 700) a distingué deux types de campements : les uns, de trois mètres sur quatre avec une concentration de microlithes et un foyer et les autres, se caractérisant par la présence de grandes structures ( 6 x 4 mètres) appelées "huttes", avec deux concentrations de microlithes et deux foyers, représentant deux unités d'occupation habitées par des «familles nucléaires ». Quant au territoire polonais, les données sont fournies par le site de Mokracz étudié par E. Niesiolowska-Śreniowska qui indique que les campements mésolithiques datant de la troisième et de la quatrième phase d'occupation constituent les vestiges témoignant de la cohabitation de deux familles (Niesiolowska-Śreniowska 1998 - p. 113-114).

74 A la lumière de ce qui précède, il apparaît que les campements de la culture janislawicienne découverts dans les tranchées 4 et 7 étaient composés de deux unités de configuration similaire, ce qui témoigne d'une certaine pérennité du modèle 
d'aménagement de l'espace. Un modèle identique de l'organisation spatiale des camps mésolithiques a été enregistré sur le gisement de Ruffey-sur-Seille (Séara, Lena 2002 p. 271).

\section{3 - Occupation postjanislavicienne}

\subsection{2 - Tranchée 2} laminaires, ce qui laisse présumer de l'existence de deux zones d'activité : atelier de débitage et aire de travaux domestiques où des outils sur éclats et des outils laminaires étaient utilisés (fig. 21-2). Des amas semblables d'outils sur éclats ont été notés sur le site de Gramsbergen (Johansen, Stapert 1997/1998 - p. 42). L'existence des concentrations séparées d'outils laminaires et d'outils sur éclats peut s'expliquer par la variété des tâches effectuées à différents endroits. Il convient de rappeler, à titre d'exemple, le site mésolithique de Vaenget Nord au Danemark où, autour du foyer situé dans la partie centrale du campement, on travaillait le bois de cervidés tandis que sa périphérie était réservée au travail des peaux (Jensen, Petersen 1985 - p. 49-50). Ces deux zones d'activité ont laissé des traces sous forme de deux dépôts différents d'outils : le travail du bois de cervidé (racloirs) et celui des peaux (grattoirs et lames).

\section{Conclusions}

L'analyse spatiale des occupations du Paléolithique final et du Mésolithique a mis en évidence des différences significatives dans l'organisation et l'aménagement des campements et des lieux de travail du silex.

$\mathrm{Au}$ Paléolithique, un processus bien particulier caractérise la formation des campements-ateliers (tranchée 4 et 9). Dans les sources archéologiques, il s'exprime par la double séquence d'accumulation du matériel lithique, ce dont témoignent les traces évidentes de nettoyage ou déblayage de restes de débitage. Chaque épisode concernait deux ateliers contemporains. Le déblayage de déchets de fabrication suggère qu'il était d'usage de revenir à plusieurs reprises dans le même lieu.

PALEO, 24 | 2013 
$80 \mathrm{Au}$ Mésolithique, l'économie lithique de certains campements présente un modèle hiérarchisé de fabrication d'outils. Les structures spatiales observées dans les tranchées 4 et 7 (fig. 16-3-4) reflètent ce schéma qui illustre les rapports entre le débitage laminaire et le débitage sur éclats. Le mode opératoire était le suivant : production de lames puis transformation des produits en microlithes qui constituent l'essentiel de la panoplie d'outils (Galiński 2002 - p. 320) enfin la production secondaire d'éclats (fig. 11-1), dont témoigne entre autres, le réemploi des nucléus à lames.

81 Les outils découverts sur place montrent que le débitage qui les a produits était étritement lié à une demande déclats. Ceci permet de conclure à l'existence d'un rapport spécifique entre le tailleur de silex et les opérations qu'il exécute. Les outils en silex étaient très vraisemblablement utilisés à l'endroit où ils étaient fabriqués. Leur usage se limitait à de brèves opérations, parfois une seule, après quoi ils étaient rejetés.

L'occupation mésolithique de Nieborowa se caractérise par la présence de campements composés de deux unités d'occupation contemporaines (tranchées 2, 4 et 7).

L'étude de l'implantation et de l'aménagement des campements paléolithiques et mésolithiques dans la microrégion de Nieborowa en Polésie de Lublin fait ressortir des différences dans l'organisation spatiale de ceux-ci. Ces divergences sont à mettre au compte du choix d'un modèle économique spécifique chez les chasseurs-cueilleurs du Paléolithique et du Mésolithique.

\section{BIBLIOGRAPHIE}

ANDREFSKY Jr. W. 2009 - The Analysis of Stone Tool Procurement, Production, and Maintenance. Journal of Archaeological Research, 17, p. 65-103.

AUDOUZE F., CAHEN D., KEELEY L.H., SCHMIDER B. 1981 - Le site magdalénien du buisson campin à Verberie. Gallia Préhistoire, 24, p. 100-143.

BODU P., KARLIN C., PLOUX S. 1990 - Who's who ? The Magdalenian flintknappers of Pincevent, France. In : E. Cziesla, S. Eickhoff, N. Arts, D. Winter (Ed.), The big puzzle. Studies in Modern Archaeology, Bonn, p. 143-164.

BOROŃ T. 2004 - Układy przestrzenne w krzemienicach kultury janisławickiej na podstawie zespołów krzemiennych z wykopów 4 i 7 ze stanowiska Nieborowa I, gm. Sawin, woj, lubelskie. Archeologia Polski, 49, p. 7-32.

BOROŃ T. 2006 - Organizacja przestrzeni w krzemienicach mazowszańskich na przykladzie zespolów krzemiennych ze stanowiska Nieborowa I, gm. Sawin, woj. lubelskie. Archeologia Polski, 51, p. 13-41.

BRONOWICKI J., BOBAK D. 2003 - Schyłkowy paleolit i mezolit na stanowisku Ślęza 11/12, pow. Wroclaw. In : B. Gediga (Ed.), Archeologiczne Zeszyty Autostradowe, z. 2, Badania na autostradzie A 4, cz.1, Wrocław, p. 9-35. 
CAHEN D. 1984 - Interprétations nouvelles pour le site paléolithique final de Meer II, Belgique. In : H. Berke, J. Hahn, C.J. Kind (Ed.), Jungpaläolithische siedlungsstrukturen in Europa, Verlag Archaeologica Venatoria, Institut für Urgeschite der Universität Tübingen, p. 241-250.

CAHEN D., KEELEY L.K., VAN NOTEN F.L. 1979 - Stone Tools, Toolkits, and Human Behavior in Prehistory. Current Anthropology, 20, n 4, p. 661-683.

CAHEN D., KARLIN C., KEELEY L.K., VAN NOTEN F. L. 1980 - Méthodes d'analyse technique, spatiale et fonctionnelle d'ensembles lithiques. Helinium, 20, z. 3, p. 209-260.

CARR C. 1991 - Left in the Dust : Contextual Information in Model-Focused Archaeology. In : E.M. Kroll T D. Price (Ed.), The Interpretation of Archaeological Spatial Patterning. Plenum Press, New York and London, p. 221-256.

CHMIELEWSKA M. 1954 Grób kultury tardenuaskiej w Janisławicach, woj. Skierniewice, Wiadomości Archeologiczne, t. 20, z. 1, p. 23-48.

CZIESLA E. 1990 - On refitting of stone artifacts. In : E. Cziesla, S. Eickhoff, N. Arts, D. Winter (Ed.), The big puzzle. Studies in Modern Archaeology, Bonn, p. 9-44.

FIEDORCZUK J. 2006 - Final Paleolithic Camp Organization - as seen from the perspective of lithic artifacts refitting. Warszawa, IAE PAN, $167 \mathrm{p}$.

GALIŃSKI T. 2002 - Społeczeństwa mezolityczne. Osadnictwo, gospodarka, kultura łowiecka w VIII-IV tysiĄcleciu p.n.e. na terenie Europy. Seria Archeologiczna, Bibliotek Naukowa Szczecin, 406 pp. 1997 Mezolit Europy, Szczecin, 259 p.

GRÖN O. 1987 - Dwelling organization - a key to the understanding of social structure in old Stone Age societies? An example from the Maglemose culture. Archaeologia Interregionalis. New in Stone Age Archaeology, p. 63-85.

GRÖN O. 2003 - Mesolithic dwelling places in south Scandinavia : their definition and social interpretation. Antiquity, 77, p. 685-708.

GUMIŃSKI W. 1999 - Kultura Zedmar a kultura Narva. Razem czy osobno. Światowit, 1, fascykuł B, p. 59-69.

GUMIŃSKI W. 2001 - Kultura Zedmar. Na rubieży neolitu zachodniego“. In : J. Czebreszuk, M. Kryvalcevič P. Makarowicz (Ed.), Od neolityzacji do poczĄtków epoki brĄzu. Przemiany kulturowe w miĘdzyrzeczu Odry i Dniepru miĘdzy VI i II tys. przed Chr, Archaeologia Bimaris, t. 2, Wydawnictwo Poznańskie, Poznań, p. 133-154.

JENSEN. H.J., PETERSEN E.B. 1985 - A functional study of lithics from Vænget Nord, a mesolithic site at Vedbæk, N. E. Sjælland. Journal of Danish Archaeology, 4, p. 40-51.

JOHANSEN L., STAPERT D. 1997/1998 - Two epi-ahrensburgian sites in the Northern Netherlands : Oudehaske (Friesland) and Gramsbergen (Overijssel). Paleohistoria, 39-40, p. 1-87.

KEELEY H.L. 1991 - Tool use and spatial patterning : complications and solution. In : E.M. Kroll, T.D. Price (Ed.), The Interpretation of Archaeological Spatial Patterning, New York, Plenum Press, p. 257-268.

KOZŁOWSKI S. K. 1972 - Pradzieje ziem polskich od IX do V tysiĄclecia p.n.e., Państwowe Wydawnictwo Naukowe, Warszawa.

KOZŁOWSKI S. K. 1989 - Mesolithic in Poland. A new approach, Wydawnictwa Uniwersytetu Warszawskiego, Warszawa. 
KOZŁOWSKI S. K. 2007 - Mezolit - miĘdzy wschodem a zachodem. In : L. Bakalarska (ed.), Wspólnota dziedzictwa archeologicznego ziem Ukrainy i Polski. Materiały z konferencji zorganizowanej przez Ośrodek Ochrony Dziedzictwa Archeologicznego, Łańcut (26-28 X 2005 r.), Krajowy Ośrodek Badań i Dokumentacji Zabytków, Warszawa, p. 108-114.

MASOJĆ M. 2004 - The Mesolithic in Lower Silesia in the light of settlement phenomena of the Kaczawa river basin. Studia Archeologiczne, 35.

NIESIOŁOWSKA - ŚRENIOWSKA E. 1998 - Warunki egzystencji i organizacja przestrzenna obozowiska późnomezolitycznego w Mokraczu, w Polsce Środkowej, Prace i Materiały Muzeum Archeologicznego i Etnograficznego w Łodzi. Seria Archeologiczna, nr 39, p. 65-128.

OLAUSSON D. 1986 - Intrasite Spatial Analysis in Scandinavian Stone Age Research. Papers of the Archaeological Institute University of Lund 1985-86, 6, p. 5-24.

OLIVE M. 1997 - Foyer domestique ou foyer annexe. Les modes d'occupation de l'espace des Magdaléniens d'Étiolles. Gallia Préhistoire, 39, p. 85-107.

PASTY J-F., ALIX P., PELLETIER D., COMBES P. 2011 Approche économique et spatiale du campement azilien des Varennes à Pérignat-sur-Allier (Puy-de-Dôme). Bulletin de la Société préhistorique française, 108, n. 1, p. 53-72.

SCHIFFER M.B. 1976 - Behavioral Archeology, Academic Press New York, San Francisco, London, $215 \mathrm{p}$.

SCHILD R. 1980 - Introduction to dynamic technological analysis of chipped stone assemblages. In : R. Schild (Ed.), Unconventional Archaeology. New approaches and goals in Polish archaeology, Ossolineum Wrocław, Warszawa, Kraków, Gdańsk, p. 57-85.

SCHILD R. 1984 - Terminal Paleolithic of the North European Plain : A review of lost chances, potential, and hopes. Advances in World Archaeology, 3, p. 193-274.

SCHILD R. 1996 - The North European Plain and Eastern Sub-Balticum between 12, 700 and 8, 000 BP. In : L.G. Straus, B.V. Eriksen, J.M. Erlandson, D.R. Yesner (Ed.), Humans at the end of the ice age. The archaeology of the pleistocene-holocene transition, New York-London, p. 129-157.

SCHILD R., MARCZAK M., KRÓLIK H. 1975 - Późny Mezolit. Próba wieloaspektowej analizy otwartych stanowisk piaskowych. Zakład Narodowy Imienia Ossolińskich. Wroclaw, Warszawa, Gdańsk, Kraków, 262 p.

SCHMIDER B. 1984 - Les habitations magdaléniennes de Marsagny (vallée de L'Yonne, France). In : H. Berke, J. Hahn, C. J. Kind (Ed.), Jungpaläolithische siedlungsstrukturen in Europa, Verlag Archaeologica Venatoria, Institut für Urgeschite der Universität Tübingen, p. 169-180.

SÉARA F., A. LENA 2002 - Organisation spatiale. In : F. Séara, S. Rotillon, C. Cupillard (Ed.), Campements mésolithiques en Bresse jurassienne. Choisey et Ruffey-sur-Seille, Documents d'archéologie française, 92, Éditions de la Maison des Sciences de l'Homme, Paris, p. 211-309.

SZYMCZAK K. 2003 - Kultura janislawicka/ krĄg kultur janislawickich - rozwój poglĄdów i stan badań. In : E. Kawałkowa (Ed.), Kultura janisławicka w Polsce północno-wschodniej i na terenach sĄsiednich, OstrolekĘka, p. 7-17.

TABORIN Y. 1994 - Environnements et habitats magdaléniens dans le centre du Bassin parisien. Documents d'archéologie française, 43, Éditions de la Maison des Sciences de l'Homme Paris, $189 \mathrm{p}$.

TOMASZEWSKI A. J. 1986 - Metoda składanek wytworów kamiennych i jej walory poznawcze. Archeologia Polski, 31, p. 239-273. 
WENZEL S., JAGU D. 2010 - L'habitat autour du foyer T5/T6 dans le gisement du Magdalénien Final de Cepoy (Loiret, France). In : M. Połtowicz-Bobak, D. Bobak (Ed.), The Magdalenian in Central Europe. New finds and concepts, Mitel, Rzeszów, p. 71-83.

\section{RÉSUMÉS}

L'analyse spatio-temporelle des campements de l'Âge de pierre dans la Polésie de Lublin illustre deux phases d'occupation: le Paléolithique supérieur (ensembles mazoviens) et le Mésolithique (culture de Janislavice). Les campements mazoviens des tranchées 4 et 9 constituent les vestiges d'ateliers de débitage de silex. Dans les deux cas, l'accumulation du matériel lithique s'est opérée en deux temps. L'occupation de la culture janislavicienne à Nieborowa se caractérise par des campements domestiques à l'organisation spatiale diversifiée. Dans la tranchée 4 , secteur I ainsi que dans la tranchée 7, la structure des concentrations janislaviciennes se présentait de la manière suivante : la place centrale était occupée par le poste de débitage principal de nucléus et de fabrication de microlithes tandis qu'au sud et au nord, se trouvaient les aires d'activités domestiques. L'organisation spatiale des campements postjanislaviciens était différente. Dans la tranchée 2, ont été découvertes deux organisations spatiales distinctes dont les parties centrales étaient occupées par un feu de camp et dont l'espace était dévolu à l'exploitation des nucléus et à la production d'outils. Dans la tranchée 3, la planigraphie des outils et du matériel lithique démontre qu'il y avait bien deux zones d'activités distinctes: une zone de fabrication (concentration d'éclats) et une zone d'activité domestique (présence d'outillage sur éclats et d'outils laminaires).

The remains of assemblages Masovian camps found in trenches 4 and 9 are flint workshops. In both cases we perceive two phases of flint material cumulation. The settlements of Janislavian culture in Nieborowa are characterized by household camps of much differentiated spatial organization. In trench 4, sector I and in trench 7 the spatial structure of Janislavian culture concentrations looked as follows : the central place was taken by the flint knapping area - the place of the blade core exploitation and microliths production and two concentrations of tools one in the north and other in the south (areas of household activity). Different is the spatial organization of postjanislavian camp complexes. In trench 2 two separate spatial plans with fires placed in their central parts were found, around which the area of household activity was determined (cores exploitation, tools production). In trench 3 the horizontal distribution of tools and flakes to the existence of two separate activity zones : the workshop (flake cumulation) and the zone of household activities (flakes and blades).

\section{INDEX}

Keywords : Poland, Nieborowa site, terminal Palaeolithic, Mesolithic, spatial analysis

Mots-clés : Pologne, Nieborowa, Paléolithique final, Mésolithique, analyse spatiale

\section{AUTEUR}

\section{TOMASZ BORON}

Section Âge de pierre, Institut d'Archéologie et d'Ethnologie, Académie Polonaise des Sciences, Al. Solidarności 105, 00-140 Varsovie (Pologne) - boron@iaepan.edu.pl 